\title{
Bütünleşik bulanık dematel-aas yöntemi ile tedarik zinciri performans ölçütlerinin önem ağırlıklarının belirlenmesi: Kablo sektöründe bir uygulama ${ }^{1}$
}

\author{
An integrated fuzzy dematel and anp method to determine importance \\ weights of supply chain performance criteria: Cable industry \\ application
}

\author{
Haluk Gökşen²
}

\begin{abstract}
${ }^{1}$ Bu çalışma yazarın "Tedarik Zincirinde Yenilik Yayılımının Tedarik Zinciri Performansına Etkisi: Kablo Sektöründe Bir Uygulama" başliklı doktora tezinden üretilmiştir.
\end{abstract}

2 Dr, Türk Telekom A.Ş., Ankara, Türkiye, goksenhaluk@gmail.com

ORCID: 0000-0002-9600-6348

\section{Başvuru/Submitted: 12/08/2021}

Revizyon/Revised: 12/09/2021

Kabul/Accepted: 24/09/2021

Yayın/Online Published: 25/12/2021

Atıf/Citation: Gökşen, H., Bütünleşik bulanık dematel-aas yöntemi ile tedarik zinciri performans ölçütlerinin önem ağırlıklarının belirlenmesi: Kablo sektöründe bir uygulama, bmij (2021) 9 (4) 1399-1421, doi:

https://doi.org/10.15295/bmij.v9i4.1907

\section{Öz}

Günümüz yoğun rekabet şartlarında işletmelerin başarılı olabilmesi ve rekabet üstünlüğgu sağlayabilmesi için tedarik zincirini oluşturan unsurlar arasındaki iş birliği ve bu iş birliğinin bir sonucu olan tedarik zincirinin performansı çok önemlidir. Bu çalışmanın amacı hem ülkemiz ekonomisi hem de sektörlerin dijitalleşme süreçlerinde önemli bir rol oynayan kablo sektöründe tedarik zinciri performans kriterlerinin önem ağırlıklarının belirlenmesidir. Performans kriterlerinin belirlenmesi için SCOR Modelinin 11. versiyonundan yararlanılmış olup, performans niteliklerinin \& ölçütlerinin ilişki yapısının ve ölçütlerin önem düzeylerinin saptanması amacıyla sırasıyla Bulanık DEMATEL ve Analitik A ğ Süreci yöntemleri kullanılmıştır. Buna göre; en yüksek $D+R$ değeri ile diğer niteliklerle en fazla ilişkili olan performans niteliği yanıt verilebilirlik olarak belirlenmiştir. Performans ölçütlerinin önem ağırlıkları açısından ise mükemmel sipariş karşılama oranının, toplam hizmet maliyetinin ve sipariş karşılama çevrim zamanının en önemli üç ölçüt olduğu tespit edilmiştir.

Anahtar Kelimeler: Tedarik Zinciri Performansı, SCOR Modeli, DEMATEL, Analitik A ğ Süreci

Jel Kodları: M11, M16, L96

\begin{abstract}
In today's intensely competitive environment, the cooperation between the elements that comprise the supply chain and the resultant performance of that supply chain is pivotal to the success of businesses and the attainment of competitive advantage. This study aims to determine the importance weights of the supply chain performance criteria in the cable industry, which plays a crucial role in our country's economy and the digitalization processes of the sectors. The 11th version of the SCOR Model was used to determine the performance criteria. In addition, the Fuzzy DEMATEL and Analytical Network Process methods were used to determine the relationship structure of the performance attributes \& criteria and the importance levels of the standards, respectively. Through analysis, responsiveness was defined as the most related to others by the highest $D+R$ value. Regarding importance weights of performance metrics, the perfect order fulfilment rate, total service cost and order fulfilment cycle time are the three most important criteria in terms of the importance weights of the performance criteria.
\end{abstract}

Keywords: Supply Chain Performance, SCOR Model, DEMATEL, Analytical Network Process Jel Codes: M11, M16, L96 


\section{Extended Abstract}

\section{An integrated fuzzy dematel and anp method to determine importance weights of supply chain performance criteria: Cable industry application}

\section{Literature}

Given the widespread use of supply chain management applications nowadays, the performance of the supply chain has become crucial for the chain members. Performance measurement can be defined as assessing the effectiveness and efficiency level of activity (Neely, Gregory and Platts, 1995). Firms can use various methods to measure their supply chain performance for developing new strategies. Several performance models (Supply Chain Operations Reference (SCOR) Model [Drzymalski, Odrey and Wilson, (2010); Palma-Mendoza, (2014); Lima-Junior and Ribeiro (2019); Zanon, Munhoz, Calache and Carpinetti, (2020)], Balanced Scor Card [Yang (2009); Bigliardi and Bottani (2010); Reefke and Trocchi (2013); Frederico, Garza-Reyes, Kumar and Kumar, (2020)], Economic Value Added (EVA) [Awan, Siddique and Sarwar, (2014); Mohamadi, Mowla, Abbasi and Askarifar, (2015); Alsoboa (2017); Hassanpour (2021)] and Activity Based Costing (ABC) [Bacher (2004); Askarany, Yazdifar and Askary (2010); Marwah, Thakar and Gupta (2014); Duran and Afonso (2020)]) have been published in the literature. This study aims to determine the relationships between the performance criteria and the importance levels of the requirements based on the SCOR Model in the cable sector.

\section{Design and method}

Fuzzy DEMATEL and Analytical Network Process (ANP) methods were used to determine the relationships between the performance criteria and the importance levels of the standards, respectively. In addition, face-to-face interviews were held with fifteen business representatives working in the cable industry. Following these interviews, a $5 \times 5$ performance attribute and a 10x10 performance criterion matrix were created for each business, related matrices obtained with the relevant formulas, and the results of the step-by-step application are given in Annex-1\&2.

\section{Findings and discussion}

This study determined the relationship between performance criteria in the cable industry and their importance levels. According to the results, the Reliability, Cost and Agility attribute emerged as the recipient, and the Responsiveness and Asset Management Efficiency attributes were the senders.

Reliability can be ensured by providing services to the customer and meeting their expectations in full. Therefore, the concepts of timely and complete supply and flexibility and after-sales service have a close relationship with reliability. Consequently, reliability is an element that is affected by many factors. Cost depends on the business's product line, R\&D expenditures, marketing activities and many fields of business. It directly reflects the spending, such as developing business needs, establishing a new R\&D lab, procurement of new machines to increase flexibility. Since these factors will directly affect the cost item, it is natural for the cost attribute to appear in the affected role, the recipient character. Agility is related to the company's responsiveness to order fluctuations. The timely and adequate supply of raw materials, production line flexibility and cash flow, affect firm agility significantly. Therefore, dexterity is affected by many factors. Responsiveness can be thought of as the ability of the business to fulfil orders, and Asset Management Efficiency can be considered the financial ratios owned by the company. These attributes affect many fields such as pricing, customer satisfaction, timely delivery, new investments and return of capital. For these reasons, it can be said that these attributes affect other elements, and it is natural that they appear in the sending character.

As a result of the application made based on performance criteria, Perfect Order Fulfilment, Upside Supply Chain Flexibility, Upside Supply Chain Adaptability, Downside Supply Chain Adaptability and Total Cost to Serve bars have emerged as the recipient, Order Fulfilment Cycle Time, Overall Value at Risk, Cash-to-Cash Cycle Time, Return on Supply Chain Fixed Assets and Return on Working Capital criteria have emerged as sender.

As a result of weighting the performance criteria used in the study with the ANP method, the Perfect Order Fulfilment, which is the most crucial criterion, means that the orders are delivered at the right time, in the right amount, with the completed documents and according to the customer's request. This criterion is of vital importance for the cable industry and all industries. The second important criterion, Total Cost to Serve, is the total supply chain cost of the service delivered and rendered to the customer. Finally, the third important criterion, Order Fulfilment Cycle Time, represents the average value of customer order fulfilment time. These will give the company an advantage over its competitors and ensure customer satisfaction. The related full table can be seen in Table 8 .

\section{Conclusion, recommendation and limitations}

When all the criteria for the sector are evaluated in general, it is seen that all the requirements have relative importance levels (Table 8). Since all processes are hierarchical and closely interconnected, it is necessary to provide the criterion with the highest level of importance. The attention and effort spent should be approximated for the standard with the lowest significance level. The study was applied to fifteen business representatives operating in the cable industry. Interviews could not be conducted with other companies operating in the same sector, which constitutes the limitation of the study. 


\section{Giriş}

Günümüzde tedarik zincirleri, yoğun rekabet ortamında belirsizliklere ve pazar dalgalanmalarına maruz kalmaktadır. Bu ortamlarda tedarik zincirlerini yönetmek için önemli bir çaba gerekmektedir. Tedarik ve talep sürecindeki belirsizlikler, daha kısa ürün ve teknoloji hayat eğrileri ve küresel pazarlar gibi durumlar tedarik zinciri süreçlerini risklere daha açık bir hale getirmiştir (Christopher ve Lee, 2004). Böylesine riskleri barındıran tedarik zinciri süreçlerinde, rekabet üstünlüğünün sağlanması ve sürdürülebilmesi için tedarik zinciri performans ölçütlerine uyumun etkin bir şekilde takip edilmesi gerekmektedir.

Hemen hemen hayatın her aşamasında artan dijitalleşme, beraberinde çok büyük boyutlara ulaşan veri kavramını da gündeme getirmiştir (Boz Eravc1, 2020). Söz konusu verinin dağıtımı da en az verinin üretilmesi kadar önemlidir. Kablo sektörü de verinin taşınması ve bilginin yayılımını sağlama noktasında önemli bir rol üstlenmektedir. Şekil 1'de görülebileceği üzere ülkemiz kablo ihracatında dokuz yıllık süreçte yaklaşık\%40'lık bir artış meydana gelmiştir. Bu doğrultuda kablo sektörünün Türkiye ekonomisi için büyük bir öneme sahip olduğu söylenebilir. Bu nedenle kablo sektöründeki tedarik zinciri performansının yüksek olması hem ülkemiz ekonomisi hem de sektörlerin dijitalleşme süreçleri açısından çok önemlidir.

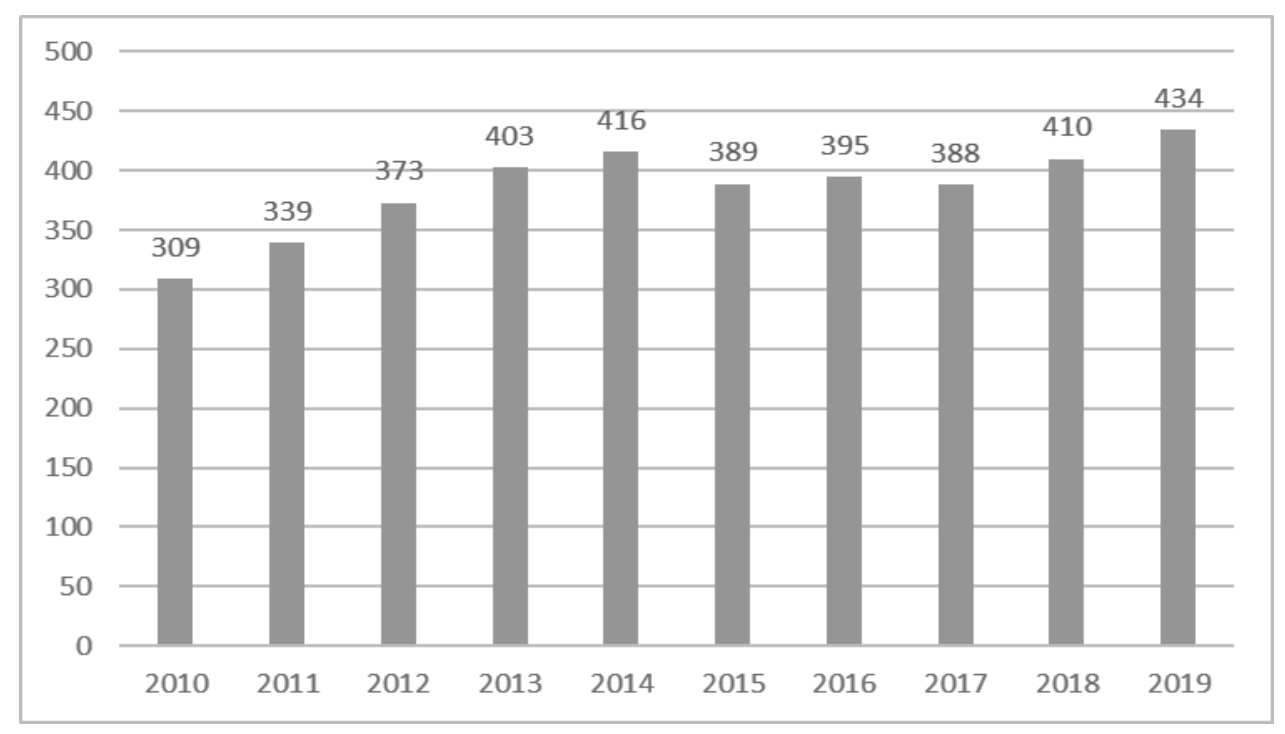

Şekil 1: Türkiye Kablo İhracat Rakamları (kiloton)

Kaynak: Kabloder (2020)

Bu çalışmanın amacı kablo sektöründe tedarik zinciri performans ölçütlerinin önem ağırlıklarının belirlenmesidir. Performans ölçütlerinin belirlenmesi için uluslararası alanda kabul görmüş olan SCOR Modelinin 11. versiyonundan yararlanılmış olup, SCOR Modeli ile belirlenen performans ölçütleri arasındaki ilişkilerin ve belirlenen ölçütlerin önem düzeylerinin saptanması amacıyla sırasıyla Bulanık DEMATEL (DEcision MAking Trial and Evaluation Laboratory) ve Analitik A $\breve{g}$ Süreci (AAS) yöntemleri kullanılmıştır. Ayrıca çalışma ile gerek dijitalleşme sürecine gerekse de ülkemiz ekonomisine bulunduğu katkı açısından önemli bir rol oynayan kablo sektöründe yöneticilerin, performans ölçütlerini daha iyi bir şekilde değerlendirebilmesi ve önceliklendirebilmesi, performans ölçütleri arasında saptanan ilişki neticesinde ise sektörün performansını artırabilecek yeni stratejiler geliştirebilmeleri amaçlanmaktadır.

Çalışmanın ilk bölümü olan kavramsal çerçeve bölümünde tedarik zinciri, tedarik zinciri yönetimi, tedarik zinciri performansı ve SCOR Modeli kavramları irdelenmiştir. İkinci bölümde ise performans ölçümlerine yönelik yapılan literatürdeki çalışmalara yer verilmiştir. Tedarik zinciri performans setinin ilişki yapısı ve önem düzeylerinin belirlenmesi için kullanılan teknikler üçüncü bölümde, uygulama ve analiz sonuçlarına ise son bölümde yer verilmiştir. 


\section{Kavramsal çerçeve}

\section{Tedarik zinciri ve tedarik zinciri yönetimi}

Tedarik zinciri, hammaddenin sağlanarak, ara ürün ve müşteriye sunulacak nihai ürünler elde edilmesi olarak tanımlanabilir. Ayrıca tedarik zinciri söz konusu ürünlerin dağıtım sürecinde yer alan üretici ve dağıtıcıların oluşturduğu bir ağdır (Lee ve Billington, 1992:66). Fox (1997)'ye göre ise tedarik zinciri hammaddeden son kullanıcıya kadar olan tüm ürün hareketlerini kapsamakta olup, satın alma, sipariş süreci, üretim planlama, tedarik envanter kontrolü, nakliye, depolama ve müşteri hizmetleri gibi aktiviteleri içermektedir. Önemli olan, tüm bu aktiviteleri bilişim sistemi içerisinde biçimlendirip ekrana aktararak tedarik zincirinin bir bütün olarak kontrolünü sağlamaktır.

Yapılan tanımlardan da anlaşılabileceği üzere işletmelerin hayatlarını devam ettirebilmeleri için zincirdeki diğer üyeler ve zincirin bütünü ile olan koordinasyon yeteneği çok önemlidir. Tedarik zinciri boyunca her yönden akışın verimli olması zincire dahil olan bütün paydaşlar için olumlu bir durum oluşturacaktır. Bu noktada bütünleşik bir sistem olarak ifade edilebilen tedarik zinciri kavramı aşağıdaki yararları sağlamaktır (Yörükoğlu, 2013:7):

- Ham maddelerin temin edilmesi ve ürüne dönüştürülmesi,

- Ürünlere değer katılarak fark yaratılması,

- Ürünlerin müşteri, perakendeci ve ilgili paydaşlara dağıtılması,

- Zinciri oluşturan farklı iş kuruluşları arasındaki bilgi paylaşım imkânının oluşturulması.

İşletmelerin küreselleşmenin de etkisiyle günümüzde değişen istek ve ihtiyaçlara daha hızlı ve daha tatmin edici şekilde cevap vermek zorunda olduğu söylenebilir. Bu nedenle müşteriye kadar uzanan yapıda tedarik zinciri giderek karmaşıklaşmakta ve kontrolü güçleşmektedir. Bununla beraber tedarik zincirindeki depolama, nakliye vb. diğer bileşenlerin önemi artmakta olup, söz konusu bileşenleri dikkate alarak tedarik zincirinde dengeyi yakalamak oldukça önemlidir. Bu dengeyi koruyabilmenin yolu ise tedarik zincirinin etkin, verimli ve değişimlere anında cevap verebilecek nitelikte dinamik bir biçimde yönetilmesidir.

Tedarik zinciri yönetimi Monczka, Handfield ve Trent (2004)'e göre bütün fonksiyonlarından, her bir aşamadaki tedarikçilere kadar toplam sistem perspektifini kullanarak, en öncelikli amacı malzemelerin kontrol edilmesi, kaynakların ve akışın yönetimi ile entegrasyonu olan bir kavramdır. Mentzer, Dewitt, Keebler, Min, Nix, Smith ve Zacharıa (2001)'e göre ise tedarik zinciri yönetimi, bir bütün olarak tedarik zincirinin ve münferit olarak firmaların uzun dönem performanslarını artırmak için geleneksel iş fonksiyonlarının, belirli bir firmaya ait iş fonksiyonları arasındaki taktiklerin ve tedarik zinciri içerisindeki işlerin sistemli ve stratejik koordinasyonudur.

Günümüzde bu amaçların sağlanabilmesinin, tedarik zinciri üyeleri arasındaki iş birliği ile doğrudan ilişkili olduğu söylenebilir. İşletmelerin varlıklarını sürdürebilmeleri için çevreleri ile devamlı iletişim halinde olmaları önemli olup, iletişimin etkinliği ancak iyi uygulanabilen tedarik zinciri yönetimi sayesinde sağlanabilecektir.

\section{Tedarik zinciri performansı ve SCOR modeli}

Günümüzde tedarik zinciri yönetimi uygulamalarının yaygınlaşması ile tedarik zincirinin performansı da zincir üyeleri için oldukça önemli bir konuma gelmiştir. Tedarik zinciri performans sonuçları işletmeleri doğrudan etkilediğinden dolayı performans sonuçlarının ölçümü ve analizi performansın iyileşip iyileşmediği konusunda işletmelere yol gösterici bilgiler verebilmektedir.

Performans ölçümü; bir faaliyetin etkenliğinin ve etkinlik düzeyinin belirlenmesi, performans ölçütü; söz konusu etkinliği tespit etmek amacıyla kullanılan göstergeler, performans ölçüm sistemi ise göstergelerin oluşturduğu bütünlük olarak ifade edilebilir (Neely vd., 1995:80).

Tedarik zinciri performansı ölçümünü önemli kılan unsurları şu şekilde sıralamak mümkündür (Başkol, 2013:72):

- Ölçümler davranış ve dolaylı yoldan performans kontrolü açısından önem arz etmektedir.

- Önemli ölçüm yöntemleri işletmenin tedarik zincirini geliştirme hedefi kapsamında işletmenin takip edeceği bir yön ve doğrultu sağlar.

- Performans ölçümünde önemli olan yöntemlerin kullanılmaması veya yanlış yöntem seçimi tedarik zinciri performansını olumsuz yönde etkiler. 
- Performans ölçümü yerine gerçekleşen olaylar sonucuna göre aksiyon alan işletmeler etkin olarak tedarik zincirini yürütemeyeceklerdir.

SCOR Modeli (Supply Chain Operations Reference Model); 1996 yılında Tedarik Zinciri Konseyi (SCC-Supply Chain Council) tarafından (üye işletmelerce yapılan çalışmalar neticesinde) oluşturulan, endüstriyel standartların belirlenmesi amacıyla tedarik zinciri yönetimi için standart bir metodoloji sağlayan, fonksiyonların ve amaçların birbirleri ile çeliştiği yapılarda ortak performans standardı sağlayan bir modeldir.

Tedarik zinciri performans ölçümü için geliştirilen SCOR Modelini 2002 yılında DCOR (Design Chain Operations Reference) Modeli, 2006 yllinda CCOR (Customer Chain Operations Reference) Modeli ve 2012 yılında PLCOR (Product Lifecycle Operations Reference) modeli izlemiştir. Ayrıca SCOR, DCOR, CCOR ve PLCOR modellerinin yanı sıra etkin tedarik zinciri liderlerinin yeteneklerini gelişmeye odaklanan yeni nesil M4SC (Managing for Supply Chain Performance) modeli de geliştirilmiştir.

SCOR Modeli işletme amaç, strateji, teknoloji ve operasyonları bütünsel olarak ele alan ve geniş bir yelpazede kabul gören bir model olarak tasarlanmıştır. SCOR Modeli, talebin başlangıçtan sona kadar olan karşılama elemanlarının bütününü ifade etmektedir. Başlangıçtan sona doğru olan süreçte talep veya tahmin, başlangıç sinyalini, son fatura ve ödeme ise talebin karşılandığı son sinyali içermektedir (Wondergem, 2004:27). Bu doğrultuda SCOR Modelini uygulayacak şirketlerin mevcut durum analizi ("as is" analizi) yaparak SCOR Modelinin önerdiği süreçlere göre yeniden yapılanmaları ("to be" analizi) gerekmektedir. Analizlerin ardından standart performans ölçütleri ile kıyaslama (benchmarking) çalışmaları yapılmakta olup son olarak başarılı performanslar temel alınarak iyileşme gereken noktaların tespit edilip tedarik zinciri performansının artırılması yönünde çalışmalar yapılmaktadır.

Bu kapsamda etkin bir biçimde uygulanması sonucunda SCOR Modelinin sağladığı başlıca yararları aşağıdaki gibi sıralanabilir (Tanyaş, 2009):

- $\% 16-\% 18$ teslimat performansinda gelişme,

- $\% 25-\% 60$ stok seviyesinde azalma,

- $\% 30-\% 50$ çevrim zamanlarında iyileşme,

- $\% 25-\% 80$ doğru tahmin yapmada iyileşme,

- $\quad \% 10-\% 16$ toplam verimlilik artışı,

- $\% 25-\% 50$ tedarik zinciri maliyetlerinde iyileşme,

- $\% 20-\% 30$ sipariş karşılama oranında iyileşme,

- $\% 10-\% 20$ kapasite kullanımında artış.

SCOR modelinde süreçleri daha ayrıntılı ve anlaşılır bir şekilde ele almak için farklı seviyelerde modellemeler yapılmaktadır. Temel olarak SCOR Modeli dört seviyede incelenmektedir:

- Seviye 1 (En Üst Seviye - Süreç Tipleri),

- Seviye 2 (Konfigürasyon Seviyesi - Süreç Kategorileri),

- Seviye 3 (Süreç Eleman Seviyesi - Ayrıştırılmış Süreçler),

- Seviye 4 (Uygulama Seviyesi - Ayrıştırılmış Süreç Elemanları).

Bu çalışma kapsamında SCOR Modeli Seviye 1 performans metriklerinden yararlanılmıştır (Tablo 1). 
Tablo 1: SCOR Modeli Seviye 1 Performans Metrikleri

\begin{tabular}{|c|c|c|c|}
\hline $\begin{array}{l}\text { Performans } \\
\text { Nitelikleri }\end{array}$ & $\begin{array}{c}\text { Performans Nitelikleri } \\
\text { Tanımları }\end{array}$ & $\begin{array}{l}\text { Performans } \\
\text { Ölçütleri }\end{array}$ & Performans Ölçütleri Tanımları \\
\hline Güvenirlilik & $\begin{array}{l}\text { Güvenilirlik, beklenilen } \\
\text { performans değerini } \\
\text { sağlama yeteneği olup, } \\
\text { sürecin sonuçlarını } \\
\text { öngörmeye odaklanmıştır. } \\
\text { Ölçüt, teslimatın zamanında } \\
\text { gerçekleştirilmesi, doğru } \\
\text { miktarda ve doğru kalitede } \\
\text { olması gibi kavramları } \\
\text { içermektedir. }\end{array}$ & $\begin{array}{l}\text { Mükemmel Sipariş } \\
\text { Karşılama Oranı } \\
\text { (RL.1.1) }\end{array}$ & $\begin{array}{l}\text { Siparişlerin müşterinin isteğine göre doğru zamanda, } \\
\text { doğru miktarda, tamamlanmış belgeleri ile hasarsız } \\
\text { ulaşmasını ifade eder. }\end{array}$ \\
\hline Yantt Verebilirlik & $\begin{array}{l}\text { Bir tedarik zincirinin } \\
\text { müşteriye ürün sağlamadaki } \\
\text { hızını ifade etmektedir. }\end{array}$ & $\begin{array}{l}\text { Sipariş Karşılama } \\
\text { Çevrim Zamanı } \\
\text { (RS.1.1) }\end{array}$ & $\begin{array}{l}\text { Müşteri siparişlerinin yerine getirilme süresinin ortalama } \\
\text { değerini ifade etmekte olup, siparişin alınıp müşteri } \\
\text { tarafından ürünün kabul edilmesine dek olan süreyi } \\
\text { kapsamaktadır. }\end{array}$ \\
\hline \multirow{4}{*}{ Çeviklik } & \multirow{4}{*}{$\begin{array}{l}\text { Rekabetçi avantaj kazanmak } \\
\text { için bir tedarik zincirinin } \\
\text { pazardaki değişikliklere } \\
\text { yanit vermedeki çevikliğini } \\
\text { ifade etmektedir. }\end{array}$} & $\begin{array}{l}\text { Üst Tedarik Zinciri } \\
\text { Esnekliği (AG.1.1) }\end{array}$ & $\begin{array}{l}\text { İşletmenin plansız ve sürdürülebilir olarak yüzde } 20 \text { fazla } \\
\text { ürün teslim edebilme durumuna gelmek için gereken } \\
\text { minumum zaman ile ilgilidir. }\end{array}$ \\
\hline & & $\begin{array}{l}\text { Üst Tedarik Zinciri } \\
\text { Adaptasyonu } \\
\text { (AG.1.2) }\end{array}$ & $\begin{array}{l}\text { Üst tedarik zinciri adaptasyonu işletmenin sürdürülebilir } \\
\text { şekilde ulaşabileceği maksimum teslim ettiği miktar ile } \\
\text { ilgilidir. }\end{array}$ \\
\hline & & $\begin{array}{l}\text { Alt Tedarik Zinciri } \\
\text { Adaptasyonu } \\
\text { (AG.1.3) }\end{array}$ & $\begin{array}{l}\text { Ceza maliyeti ve envanter maliyeti olmaksızın teslimattan } \\
30 \text { gün öncesinde siparişlerdeki sürdürülebilir azalma } \\
\text { yüzdesi ile ilgilidir. }\end{array}$ \\
\hline & & $\begin{array}{l}\text { Ortalama Riske } \\
\text { Maruz Değer (AG. } \\
\text { 1.4) }\end{array}$ & $\begin{array}{l}\text { Ortalama Riske Maruz Değer finans endüstrisinde riskin } \\
\text { etkisini anlamak için yaygın olarak kullanılan tanınmış bir } \\
\text { risk ölçütüdür. Tedarik zincirinde risk kavramı } \\
\text { tedarikçinin tedarikçisinden başlayarak müşterinin } \\
\text { müşterisine kadar uzanmaktadır. Tedarik zinciri risk } \\
\text { değeri, tedarik zinciri fonksiyonlarını (Plan, Tedarik, } \\
\text { Üretim, Dağıtım ve İade) ya da anahtar bağlantıları } \\
\text { etkileyebilecek risklerin gerçekleşme olasılığının } \\
\text { toplamıdır. }\end{array}$ \\
\hline Maliyet & $\begin{array}{l}\text { Tedarik zincirini } \\
\text { gerçekleştirmeyle bağlantılı } \\
\text { maliyetleri ifade etmektedir. }\end{array}$ & $\begin{array}{l}\text { Toplam Hizmet } \\
\text { Maliyeti (CO 1.001) }\end{array}$ & $\begin{array}{l}\text { Toplam hizmet maliyeti müşteriye teslim edilen ve verilen } \\
\text { hizmetin toplam tedarik zinciri maliyetidir. Toplam } \\
\text { hizmet maliyeti, planlama maliyeti, hammadde maliyeti, } \\
\text { ürün maliyeti, üretim maliyeti, yeniden üretim maliyeti, } \\
\text { yenileme maliyeti, tamir ve bakım maliyeti, sipariş } \\
\text { yönetim maliyeti, iade maliyeti, dağıtım maliyeti ve } \\
\text { hizmet maliyetlerini içermektedir. }\end{array}$ \\
\hline \multirow{3}{*}{$\begin{array}{l}\text { Varlık Yönetimi } \\
\text { Etkinliği }\end{array}$} & \multirow{3}{*}{$\begin{array}{l}\text { Varlıkların verimli bir } \\
\text { şekilde kullanılması } \\
\text { yeteneğidir. Varlık yönetimi, } \\
\text { envanter azaltılması ve } \\
\text { iç/dış kaynak kullanımını } \\
\text { kapsar. }\end{array}$} & $\begin{array}{l}\text { Nakitten Nakite } \\
\text { Çevrim Zamanı } \\
\text { (AM.1.1) }\end{array}$ & $\begin{array}{l}\text { Nakitten nakite çevrim zamanı, nakdin ürünlere ve } \\
\text { servislere yatırıldığı zaman ile yatırımın nakit ürettiği } \\
\text { zaman arasındaki sürekliliği temsil eder. }\end{array}$ \\
\hline & & $\begin{array}{l}\text { Tedarik Zinciri } \\
\text { Sabit Varlıkların } \\
\text { Geri Dönüşü } \\
\text { (AM.1.2) }\end{array}$ & $\begin{array}{l}\text { Tedarik zinciri sabit varlıkların geri dönüş oranı, } \\
\text { işletmenin varlıklarının gelir yaratma yönünde ne kadar } \\
\text { etkin yönetildiğini ortaya koyar. }\end{array}$ \\
\hline & & $\begin{array}{l}\text { İşletme } \\
\text { Sermayesinin Geri } \\
\text { Dönüşüu (AM.1.3) }\end{array}$ & 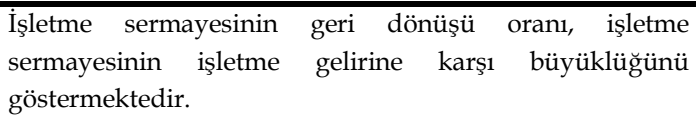 \\
\hline
\end{tabular}

Kaynak: SCC, 2012

\section{Literatür taraması}

Literatürde çeşitli modeller ile performans ölçümlerine ilişkin çalışmaların olduğu gözlenmiş olup, çalışma kapsamında incelenen kategorilerde yapılmış bazı çalışmalar Tablo 2' de gösterilmiştir. 
Tablo 2: Tedarik Zinciri Performans Ölçümüne Yönelik Yapılan Genel Çalışmalar

\begin{tabular}{|c|c|}
\hline Yazar(lar) & Model \\
\hline Lai, Ngai ve Cheng (2002) & \multirow{12}{*}{ SCOR } \\
\hline Berrah ve Cliville (2007) & \\
\hline Wong ve Wong (2007) & \\
\hline Wong, Jaruphongsa, Lee ve Wong (2007) & \\
\hline Theeranuphattana ve John (2008) & \\
\hline Wong, Jaruphongsa ve Lee (2008) & \\
\hline Cai, Liu, Xiao ve Liu (2009) & \\
\hline Wong (2009) & \\
\hline Drzymalski vd. (2010) & \\
\hline Palma-Mendoza (2014) & \\
\hline Lima-Junior ve Ribeiro (2019) & \\
\hline Zanon vd. (2020) & \\
\hline Gunasekaran, Patel ve Tırtıroğlu (2001) & \multirow{9}{*}{ Balanced Scor Card } \\
\hline Bhagwat ve Sharma (2007a) & \\
\hline Bhagwat ve Sharma (2007b) & \\
\hline Varma, Wadhwa ve Deshmukh (2008) & \\
\hline Bhagwat ve Sharma (2009) & \\
\hline Yang (2009) & \\
\hline Bigliardi ve Bottani (2010) & \\
\hline Reefke ve Trocchi (2013) & \\
\hline Frederico vd. (2020) & \\
\hline Halim, Eldeeb, Habib ve Bassim (2011) & \multirow{5}{*}{ Ekonomik Katma Değer (EVA) } \\
\hline Awan vd. (2014) & \\
\hline Mohamadi vd. (2015) & \\
\hline Alsoboa (2017) & \\
\hline Hassanpour (2021) & \\
\hline Lin, Collins ve Su (2001) & \multirow{5}{*}{ Faaliyete Dayalı Maliyetlendirme (ABC) } \\
\hline Bacher (2004) & \\
\hline Askarany vd. (2010) & \\
\hline Marwah vd. (2014) & \\
\hline Duran ve Afonso (2020) & \\
\hline
\end{tabular}

Literatürde performans ölçümünde ve ayrıca tedarikçi seçim sürecinde kullanılan performans kriterlerinin kullanıldığı birçok çalışma mevcut olup, söz konusu çalışmalar kapsamında kullanılan bazı kriterler ve çalışmalar Tablo 3'te gösterilmiştir.

Yapılan literatür çalışmasında performans ölçümü ve tedarikçi seçiminde kullanılan kriterlerin bazılarının SCOR Modeli kapsamındaki seviye-1 performans nitelikleri ile aynı olduğu tespit edilmiştir (Güvenilirlik, Yanıt Verebilirlik, Esneklik ve Maliyet). Diğer performans kriterlerinin ise SCOR Modelini üst seviyelerindeki metrikler vasıtasıyla doğrudan veya dolaylı olarak desteklediği anlaşılmıştır. 
Tablo 3: Performans Kriterleri ile İlgili Yapılan Genel Çalışmalar

\begin{tabular}{|c|c|c|c|}
\hline Yazar(lar) & Kriter & Yazar(lar) & Kriter \\
\hline Sarkar ve Mohapatra (2006) & \multirow{8}{*}{ Maliyet } & Chan ve Chan (2004) & \multirow{3}{*}{ Yenilik } \\
\hline Wadhwa ve Ravindran (2007) & & Bhagwat, Chan ve Sharma (2008) & \\
\hline Xia ve $\mathrm{Wu}(2007)$ & & Thanaraksakul ve Phruksaphanrat (2009) & \\
\hline Watt, Kayis ve Willey (2010) & & Tabriz ve Alam (2014) & $\begin{array}{c}\text { Yeşil } \\
\text { Teknoloji }\end{array}$ \\
\hline Khaleie, Fasanghari ve Tavassoli (2012) & & Yurdakul ve İç (2001) & \multirow{2}{*}{$\begin{array}{l}\text { Üretim } \\
\text { Kapasitesi }\end{array}$} \\
\hline Verdecho, Rodriguez ve Alfaro-Saiz (2013) & & Sarkar ve Mohapatra (2006) & \\
\hline Haghighi, Moradi ve Salahi (2014) & & Sarkar ve Mohapatra (2006) & \multirow{2}{*}{$\begin{array}{l}\text { Yönetsel } \\
\text { Beceri }\end{array}$} \\
\hline $\begin{array}{l}\text { Luthra, Govindan, Kannan, Mangla ve Garg } \\
\text { (2017) }\end{array}$ & & Thanaraksakul ve Phruksaphanrat (2009) & \\
\hline $\begin{array}{l}\text { Aramyan, Oude Lansink, Van der vorst ve } \\
\text { Van Kooten (2007) }\end{array}$ & \multirow{2}{*}{$\begin{array}{c}\text { Yanit } \\
\text { Verilebilirlik }\end{array}$} & Jing-Rung (2008) & \multirow{2}{*}{ Güvenilirlik } \\
\hline Wang, Cheng ve Huang (2008) & & Thanaraksakul ve Phruksaphanrat (2009) & \\
\hline Verdecho, Rodriguez ve Alfaro-Saiz (2013) & \multirow{2}{*}{ Esneklik } & Tseng ve Lin (2005) & \multirow{2}{*}{ Teknoloji } \\
\hline Tabriz ve Alam (2014) & & Xia ve $\mathrm{Wu}(2007)$ & \\
\hline Sarkar ve Mohapatra (2006) & \multirow{5}{*}{ Kalite } & Sarkar ve Mohapatra (2006) & \multirow{3}{*}{$\begin{array}{l}\text { Üretim } \\
\text { Kapasitesi }\end{array}$} \\
\hline Thanaraksakul ve Phruksaphanrat (2009) & & Xia ve $\mathrm{Wu}(2007)$ & \\
\hline Verdecho, Rodriguez ve Alfaro-Saiz (2013) & & Thanaraksakul ve Phruksaphanrat (2009) & \\
\hline Nekooie, Sheikhalishahi ve Hosnavi (2015) & & Sarkar ve Mohapatra (2006) & \multirow{2}{*}{$\begin{array}{l}\text { İletişim } \\
\text { Araçları }\end{array}$} \\
\hline Paul (2015) & & Thanaraksakul ve Phruksaphanrat (2009) & \\
\hline Wadhwa ve Ravindran (2007) & \multirow{5}{*}{ Teslimat } & Van Hoek (1998) & Entegrasyon \\
\hline Thanaraksakul ve Phruksaphanrat (2009) & & $\begin{array}{l}\text { Verdecho, Rodriguez ve Alfaro-Saiz } \\
(2013)\end{array}$ & \multirow{2}{*}{ Servis } \\
\hline Kuo, Wang ve Tien (2010) & & Saad, Kunhu ve Abdalah (2016) & \\
\hline Lin, Chien ve Ting (2011) & & Chan and Qi (2003) & \multirow[b]{2}{*}{ Bilgi Zamanı } \\
\hline $\begin{array}{l}\text { Kannan, Khodaverdi, Olfat, Jafarian ve } \\
\text { Diabat (2013) }\end{array}$ & & Soni and Kodali (2010) & \\
\hline
\end{tabular}

Literatürde kablo ve ilişkili sektörlerde yapılan çalışmalar da yer almaktadır. Örneğin, Stephens (2015) yaptığı araştırma kapsamında telekomünikasyon sektörü için fiber optik kablo tedariğinde fiyat, ürün, dizayn, enerji, standart, risk, ürün ve hammadde özellikleri kriterlerine yer vermiştir. Ortiz-Barrios, Kucukaltan, Tinoco, Rodado ve Jimenez (2017)'nin kablo sektörü için son derece önemli bir hammadde olan yüksek yoğunluklu polietilen tedarikçisi seçimi üzerine yaptıkları araştırmada ise kalite, verimlilik, hizmet seviyesi, ticari politika, ürün tanıtımı, yenilik, tedarikçi konumu ve finansal performans kriterleri kullanılmıştır. Ayrıca Cheraghalipour ve Farsad (2018)'in kablo sektörü ile üretim noktasında yakın ilişkili olan plastik sektöründe yaptıkları araştırmada maliyet, kalite, teslimat, güvenilirlik, teknoloji, hizmet ve finansal durum kriterlerine yer verilmiştir.

\section{Yöntem}

Çalışmanın veri toplama zamanı 1 Ocak 2020 tarihinden önce olduğu için etik kurul izin belgesi düzenlenmemiştir.

Araştırma kapsamında aşağıda belirtilen hipotezler kurulmuş ve hipotezlerin test edilmesi için Bulanık DEMATEL ve AAS yöntemlerinden yararlanılmıştır.

Hipotez 1: Kablo sektöründe Yanıt Verilebilirlik performans niteliği diğer performans nitelikleri ile daha fazla ilişki içerisindedir.

Hipotez 2: Kablo sektöründe Toplam Hizmet Maliyeti performans ölçütü diğer tüm performans ölçütlerinden daha fazla önem ağırlığına sahiptir. 
Bu kapsamda Hipotez 1'in test edilmesi amaciyla performans nitelikleri ve performans ölçütleri arasındaki etkileyen ve etkilenen etmenlerin belirlenmesi için DEMATEL yöntemi kullanılmıştır. Lin, Chen ve Tzeng (2009)'a göre DEMATEL, kriterlerin birbirleri ile olan ilişki yapısının tespit edilmesinde ve buna dayalı bir ilişki ağı oluşturulmasına imkân tanımaktadır. DEMATEL yönteminin temel amacı, karmaşık neden - sonuç ilişkilerini görselleştirerek anlamlı sonuçlar elde etmektir. Fakat bu ilişkilerde faktörler arasındaki etkileşimin derecesinin belirlenmesi oldukça güçtür. Bunun nedeni de uzmanların faktörler arasındaki etkileşimi nicel olarak ifade etmelerinin oldukça zor olmasıdır. Bu sebeple Lin ve $\mathrm{Wu}$ (2008) DEMATEL yöntemini bulanık ortama genişletmişlerdir (Albayrak ve Erkayman, 2018).

Performans ölçütlerinin önem ağırlıklarının belirlenmesi sürecinde ve aynı zamanda Hipotez-2'nin test edilmesi amacıyla Thomas L. Saaty (1996) tarafından geliştirilen AAS yönteminden yararlanılmıştır. Jharkharia ve Shankar (2007)'ye göre AAS karar vericilere; nitel ve nicel kriterleri hiyerarşik bir yapıya bağlı olma mecburiyeti olmadan modele dâhil edebilmesi, öncelikleri tespit ederek amaç ile kriterler arasında bağlantı kurması ve öncelikleri oransal bir ölçekle belirlemesi gibi avantajlar sağlamaktadır.

$\mathrm{Bu}$ nedenle çalışma kapsamında bütünleşik Bulanık DEMATEL-AAS yöntemi kullanılmıştır. Bu yöntemlere ilişkin teorik açıklamalar aşağıda verilmiştir.

\section{Bulanık DEMATEL}

Bulanık DEMATEL yöntemi aşağıda verilen adımları kapsamaktadır (Aksakal ve Dağdeviren, 2010:907-908 ; Baykaşoğlu, Kaplanoğlu, Durmuşoğlu ve Şahin, 2013:900-902):

1. Adım - Kriterlerin Belirlenmesi ve Bulanık Skalanın Tespiti: Yöntemin ilk aşamasında kriterler belirlenerek uzman kişilerce söz konusu kriterler arası ilişkiler oluşturulur. Bu ilişkiler oluşturulduktan sonra kriterler arasındaki ikili karşılaştırılmalar Tablo $4^{\prime}$ te belirtilen bulanık ölçek vasitasiyla yapilır.

Tablo 4: Bulanık Dilsel Ölçek

\begin{tabular}{|c|c|c|}
\hline Dilsel İade & Kısaltma & Bulanık Karşılıkları \\
\hline Etki Yok & EY & $(0,00 ; 0,00 ; 0,25)$ \\
Çok Az Etkili & ÇAE & $(0,00 ; 0,25 ; 0,50)$ \\
Az Etkili & AE & $(0,25 ; 0,50 ; 0,75)$ \\
Fazla Etkili & FE & $(0,50 ; 0,75 ; 1,00)$ \\
Çok Fazla Etkili & ÇFE & $(0,75 ; 1,00 ; 1,00)$ \\
\hline
\end{tabular}

Kaynak: Wu ve Lee, 2007:503

2. Adım - Direk İlişki Matrisinin Oluşturulması: Kriterler $\left\{\mathrm{C}_{1}, \mathrm{C}_{2}, \ldots, \mathrm{C}_{\mathrm{n}}\right\}$ arasındaki ilişki düzeylerinin ölçülmesi amacıyla uzmanlar tarafından bulanık dilsel ölçek vasıtasıyla uzman sayısı kadar oluşturulan ikili karşılaştırma matrisi kullanılır. Elde edilen bulanık direk ilişki matrisi Ž olarak ifade edilir.

$$
\check{Z}_{\mathrm{ij}}=\left(l_{\mathrm{ij}}, \mathrm{n}_{\mathrm{ij}}, \mathrm{u}_{\mathrm{ij}}\right) \text { üçgensel bulanık sayısı i. faktörün j. faktörü etkileme düzeyini göstermektedir. }
$$

3. Adım - Normalleştirilmiş Direk İlişki Matrisinin Oluşturulması:

$$
\begin{gathered}
\tilde{x}_{i j}^{(k)}=\frac{\widetilde{z}_{i j}^{k}}{r^{(k)}}=\left(\frac{l_{i j}^{k}}{r^{(k)}}, \frac{n_{i j}^{(k)}}{r^{(k)}}, \frac{u_{i j}^{(k)}}{r^{(k)}}\right) \\
r^{(k)}=\max _{1<i<n}\left(\sum_{j=1}^{n} u_{i j}^{k}\right)
\end{gathered}
$$


Normalleştirilmiş direk ilişki matrisi Eşitlik 1 ve 2 vasıtasıyla oluşturulur. Eşitlik 2 kullanılarak ayrı ayrı bütün $1, \mathrm{n}$ ve $\mathrm{u}$ değerleri sütun olarak toplanır ve her sütun için bir değer bulunup, söz konusu değerlerin en büyüğü seçilerek " $r$ " elde edilir. Ardından bütün matris " $r$ " ye bölünerek normalleştirilmiş direk ilişki matrisi elde edilir. Normalleştirilmiş direk ilişki matrisi " 8 " ile gösterilir.

$$
\tilde{X}=\left[\begin{array}{cccc}
\widetilde{X_{11}} & \widetilde{X_{12}} & \ldots & \widetilde{X_{1 n}} \\
\widetilde{X^{2}} & \widetilde{X_{22}} & \ldots & \widetilde{X_{2 n}} \\
\vdots & \vdots & \ddots & \vdots \\
\widetilde{X_{n 1}} & \widetilde{X_{n 2}} & \ldots & \widetilde{X_{n n}}
\end{array}\right]
$$

4. Adım - Toplam İlişki Matrisi: Normalleştirilmiş ilişki matrisi oluşturulduktan sonra sonra Eşitlik 3 vasıtasıyla toplam ilişki matrisi elde edilir.

$$
\widetilde{T}=\widetilde{X}+\widetilde{X}^{2}+\widetilde{X}^{3}+\ldots=\sum_{i=1}^{\infty} \widetilde{X}^{i}=\widetilde{X}(I-\widetilde{X})^{-1}
$$

l, n, u üçgensel bulanık sayılarından ayrı ayrı elde edilen matrisler öncelikle birim matristen çıkarılır, ardından çıkarma işlemi sonucunda elde edilen matrisin tersi alınarak matrisin ilk haliyle çarpılır. Üç

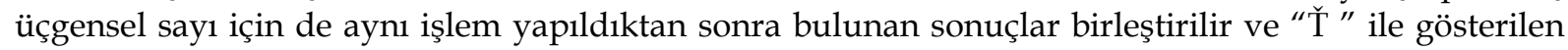
tek bir toplam ilişki matrisi elde edilir.

$$
T=\left[\begin{array}{cccc}
\widetilde{T_{11}} & \widetilde{T_{12}} & \ldots & \widetilde{T_{1 n}} \\
\widetilde{T_{21}} & \widetilde{T_{22}} & \ldots & \widetilde{T_{2 n}} \\
\vdots & \vdots & \vdots & \vdots \\
\widetilde{T_{n 1}} & \widetilde{T_{n 2}} & \ldots & \widetilde{T_{n n}}
\end{array}\right]
$$

5. Adım - Gönderici ve Alıcı Grupların Belirlenmesi: ̌̌ matrisi elde edildikten sonra $\check{\mathrm{D}}_{\mathrm{i}}$, $\check{\mathrm{T}}^{\mathrm{T}}$ matrisinde satır elemanlarının toplamı, $\check{R}_{i}$, $\breve{T}$ matrisinde sütün elemanlarının toplamı olmak üzere, $\check{D}_{i}+\check{\mathrm{R}}_{i}$ ve $\check{\mathrm{D}}_{\mathrm{i}}-\check{\mathrm{R}}_{\mathrm{i}}$ değerleri hesaplanır.

D değeri toplam ilişki matrisinde satırlar toplamını, $R$ ise sütunlar toplamını verir

$$
\begin{aligned}
& \tilde{D}_{i}=\sum_{i=1}^{n} T_{i j} \quad(\mathrm{i}=1,2, \ldots \ldots, \mathrm{n}) \\
& \tilde{R} i=\sum_{j=1}^{n} T_{i j} \quad(\mathrm{j}=1,2, \ldots \ldots, \mathrm{n})
\end{aligned}
$$

Her bir kriterin diğer kriterlerle olan ilişki seviyesi ve diğer kriterlere olan etki düzeyi her bir kriter için bulunan $\mathrm{D}-\mathrm{R}$ ve $\mathrm{D}+\mathrm{R}$ değerleri ile hesaplanmaktadır. Bu kapsamda D-R değeri bazı kriterler için pozitif, bazı kriterler için de negatif olarak bulunabilmektedir. D-R değerinin pozitif olduğu kriterler gönderici olup, söz konusu kriterlerin diğerleri üzerinde daha yüksek etkiye sahip olduğu ve daha yüksek öncelikli olduğu kabul edilmektedir. Öte yandan D-R değeri negatif ise söz konusu kriterin diğer kriterlerden daha fazla etkilendiği ve daha düşük önceliğe sahip olduğu kabul edilmektedir. Bu tip kriterler ise alıcı olarak belirtilmektedir. Ayrıca D+R değeri yüksek olan kriterler diğer kriterlerle daha fazla ilişkili, düşük olanlar ise daha az ilişkilidir (Aksakal ve Dağdeviren, 2010:908).

6. Adım - Durulaştırma: Bulunan D-R ve D+R değerleri üçgensel bulanık sayılardan elde edilmiş olup, üç değeri tek değere indirgeyebilmek için ise Eşitlik 5 formülü ile durulaştırma yöntemi uygulanır. D$R$ ve $D+R$ için durulaştırma uygulandığında formülün gösterilme şekli durulaştırma anlamına gelen "defuzzifying" in kısaltılması olan "def" olarak revize edilir.

$$
\begin{aligned}
& \widetilde{D}_{i}^{D e f}+\widetilde{R}_{i}^{D e f}=\frac{1}{4}(l+2 n+u) \\
& \widetilde{D}_{i}^{D e f}-\widetilde{R}_{i}^{D e f}=\frac{1}{4}(l+2 n+u)
\end{aligned}
$$


7. Adım - Neden- Sonuç İlişki Diyagramının Elde Edilmesi: Durulaştırma yöntemi vasıtasıyla yatay ekseni $\mathrm{D}+\mathrm{R}$, düşey ekseni $\mathrm{D}-\mathrm{R}$ olan bir koordinatta neden sonuç ilişki diyagramı çizilir ve analiz edilir (Aksakal ve Dağdeviren, 2010:908).

\section{Analitik ağ süreci}

Çalışma kapsamında kriterlerin önem düzeylerinin belirlenmesi için kullanılacak AAS uygulama süreci, dört ana aşamadan meydana gelmektedir (Saaty ve Vargas, 2006; Gencer ve Gürpınar, 2007; Tuzkaya, Önüt, Tuzkaya ve Gülsün, 2008; Saaty, 2009; Ar, 2013; Ar, Gökşen ve Tuncer, 2015):

1. Adım - Karar Problemine Ait Modelin Oluşturulması: İlk aşama kapsamında kriterler, alt kriterler ve alternatifler belirlenerek bütün kavramlar arasındaki ilişki yapısını gösteren ağ yapısı oluşturulur.

2. Adım - Ağırlıklandırılmamış Süpermatrisin Oluşturulması: Saaty'nin geliştirdiği ölçek (Tablo 5) vasıtasıyla karar vericiler ağ modeli kapsamında ikili ilişkileri değerlendirir. Ağırlıklandırılmamış Süpermatris bütün ikili karşılaştırmalar neticesinde oluşturulur.

Tablo 5: Önem Ölçeği

\begin{tabular}{|c|c|}
\hline Değerler & Tanım \\
\hline 1 & Eşit derecede önemli \\
3 & Çok az derecede önemli \\
5 & Kuvvetli derecede önemli \\
7 & Çok kuvvetli derecede önemli \\
9 & Aşırı derecede önemli \\
$2,4,6,8$ & Ara değerler \\
\hline
\end{tabular}

Kaynak: Liberatore ve Nydick, 1997:599

3. Adım - Ağırlıklandırılmış Süpermatrisin Oluşturulması: Ağırlıklandırılmış Süpermatris, Ağırlıklandırılmamış Süper matristeki değerlerin ilgili alt kriteri barındıran kriterin ağırlığı ile çarpılması sonucu elde edilir.

4. Adım - Limit Süpermatrisin Oluşturulması: Limit Süpermatris, Ağırlıklandırılmış Süpermatrisin satır değerlerinin ayn değeri buluncaya kadar büyük dereceden kuvvetinin alınmasıyla elde edilir. Limit Süpermatris'teki sütunların normalleştirilmesi sonucu alternatiflerin öncelik değerleri belirlenir.

ÇKKV tekniklerinde kararlar kriterlerin birbirleri ile kıyaslanmaları nihayetinde çıkacak sonuca göre verilmektedir. Kıyaslama sonucunda işletmelerin stratejik amaç ve hedeflerine bağlı olarak kriterlerin önem düzeyleri ve ilişki yapıları elde edilerek karar vericiye destek sağlanmaktadır.

\section{Araştırmanın bulguları}

\section{Bulanık DEMATEL yöntemi ile hiyerarşik yapının oluşturulması}

Çalışmanın bu safhasına katılmayı kabul eden ve kablo sektöründe görev yapan on beş işletme temsilcisi ile yüz yüze görüşmeler gerçekleştirilmiştir.

Yapılan görüşmeler sonucu her bir işletme için $5 \times 5$ performans niteliği, 10x10 performans ölçütü matrisi oluşturulmuş, söz konusu matrislerin ortalaması ile direkt ilişki matrisi elde edilmiş, ardından kavramsal çerçeve bölümünde belirtilen formüller vasıtasıyla normalize edilmiş ilişki matrise ulaşılmıştır. Son olarak normalize edilmiş matris, ilgili formüller ile toplam ilişki matrisine dönüştürülmüş olup, aşama aşama uygulama sonuçları Ek-1'de verilmiştir.

Toplam etki matrislerinin düzenlenmesinin ardından satır ve sütun toplamları ve farkları vasıtasıyla her bir performans niteliği ve ölçütün $D+R$ ve $D-R$ değerleri elde edilmiş ve durulaştırılmıştır. Performans niteliklerine ilişkin $D+R$ ve $D-R$ değerleri Tablo 6 'da, performans ölçütlerine ilişkin $D+R$ ve $\mathrm{D}-\mathrm{R}$ değerleri ise Tablo 7'de görülebilir.

Tablo 6: Performans Niteliklerine İlişkin D+R ve D-R Değerleri

\begin{tabular}{|c|c|c|c|}
\hline Performans Niteliği & D+R & D-R & Statü \\
\hline Güvenirlilik & 5,04 & $-1,18$ & Alıc1 \\
\hline Yanıt Verebilirlik & 6,92 & 0,95 & Gönderici \\
\hline Çeviklik & 6,11 & $-1,22$ & Alıc1 \\
\hline Maliyet & 4,65 & $-1,09$ & Alıc1 \\
\hline Varlık Yönetimi Etkinliği & 6,54 & 2,54 & Gönderici \\
\hline
\end{tabular}


Tablo 7: Performans Ölçütlerine İlişkin D+R ve D-R Değerleri

\begin{tabular}{|c|c|c|c|}
\hline Performans Ölçütü & D+R & D-R & Statü \\
\hline Mükemmel Sipariş Karşılama Oranı (RL.1.1) & 8,20 & $-0,42$ & Alıcı \\
\hline Sipariş Karşılama Çevrim Zamanı (RS.1.1) & 6,93 & 0,74 & Gönderici \\
\hline Üst Tedarik Zinciri Esnekliği (AG.1.1) & 6,84 & $-1,18$ & Alıcı \\
\hline Üst Tedarik Zinciri Adaptasyonu (AG.1.2) & 6,81 & $-2,08$ & Alıcı \\
\hline Alt Tedarik Zinciri Adaptasyonu (AG.1.3) & 6,23 & $-1,43$ & Alıcı \\
\hline Ortalama Riske Maruz Değer (AG.1.4) & 7,69 & 0,60 & Gönderici \\
\hline Toplam Hizmet Maliyeti (CO 1.001) & 6,73 & $-0,14$ & Alıcı \\
\hline Nakitten Nakite Çevrim Zamanı (AM.1.1) & 7,14 & 0,77 & Gönderici \\
\hline Tedarik Zinciri Sabit Varlıkların Geri Dönüşü (AM.1.2) & 6,96 & 1,10 & Gönderici \\
\hline İşletme Sermayesinin Geri Dönüşü (AM.1.3) & 7,59 & 2,04 & Gönderici \\
\hline
\end{tabular}

Bulanık DEMATEL uygulamasında pozitif D-R değerine sahip ölçütler diğer ölçütleri yüksek derecede etkileyen ve gönderici olarak adlandırılan, negatif D-R değerine sahip ölçütler ise diğer kriterlerden daha fazla etkilendiği kabul edilen ve alıcı olarak adlandırılan ölçütlerdir. Diğer taraftan $D+R$ değerleri, her bir ölçütün diğer ölçütler ile arasındaki ilişkiyi göstermekte ve $D+R$ değeri yüksek olan ölçütlerin diğer ölçütlerle daha fazla ilişkiye sahip olduğu kabul edilmektedir. Bu kapsamda yapılan uygulama neticesinde Güvenilirlik, Maliyet ve Çeviklik nitelikleri alıcı, Yanıt Verilebilirlik ve Varlık Yönetimi Etkinliği nitelikleri ise gönderici olarak ortaya çıkmıştır. Ayrıca Yanıt Verilebilirlik niteliğinin sahip olduğu en yüksek gönderici $D+R$ değeri ile diğer nitelikler ile daha fazla ilişkiye sahip olduğu söylenebilir.

Nitelik bazında değerlendirme yapılacak olursa sektör için elde edilen bulgular doğal karşılanabilir. Güvenilirlik müşteriye verilen eksiksiz ve beklentileri karşılayan hizmet ile sağlanabilmektedir. Dolayısıyla zamanında ve eksiksiz temin, esneklik ve satış sonrası hizmet kavramları güvenilirlik ile sıkı bir ilişkiye sahiptir. Bu noktada güvenilirlik birçok faktörün etkilediği bir unsurdur.

Maliyet, işletmenin ürün hattına, Ar-Ge harcamalarına, pazarlama faaliyetlerine vb. geliştirmelere yapacağı harcamaları doğrudan yansıtan bir niteliktir. İşletmenin yeni bir Ar-Ge laboratuvarı kurması, esnekliği artırmak için yeni makineler alması vb. faktörler maliyet kalemini doğrudan etkileyeceği için Maliyet niteliğinin etkilenen rol olan alııı karakterde ortaya çıması doğaldır.

Çeviklik işletmenin siparişteki dalgalanmalara yanıt verebilirliği ile ilişkilidir. Zamanında ve yeterli düzeyde hammadde temini ve hammaddenin ürüne dönüşmesi için gereken bütün sermayenin nakit akışlarından zamanında sağlanması firma esnekliğini ve çevikliğini önemli düzeyde etkilemektedir. Dolayısıyla Çeviklik birçok faktörden etkilenmektedir.

Yanıt Verilebilirlik işletmenin siparişleri karşılayabilme yeteneği olarak, Varlık Yönetimi Etkinliği ise işletmenin sahip olduğu finansal oranlar olarak düşünülebilir. Bu nedenle söz konusu niteliklerin iyi seviyede olması neticesinde zamanında temin ile müşteri güveni kazanılabilir ve sermayenin hızlı geri dönüşüyle yeni yatırımlar yapılabilir. Bu nedenlerden dolayı söz konusu niteliklerin başka unsurları etkilediği söylenebilmekte olup etkileyen rol olan gönderici karakterde ortaya çıkması doğaldır.

Performans ölçütü bazında yapılan uygulama neticesinde ise alıcı olarak Mükemmel Sipariş Karşılama Oranı, Üst Tedarik Zinciri Esnekliği, Üst Tedarik Zinciri Adaptasyonu, Alt Tedarik Zinciri Adaptasyonu ve Toplam Hizmet Maliyeti ölçütleri, gönderici olarak ise Sipariş Karşılama Çevrim Zamanı, Ortalama Riske Maruz Değer, Nakitten Nakite Çevrim Zamanı, Tedarik Zinciri Sabit Varlıkların Geri Dönüşü ve İşletme Sermayesinin Geri Dönüşüü ölçütleri ortaya çıkmıştır.

\section{AAS ile performans ölçüt ağırlıklarının belirlenmesi}

AAS uygulamasının başlangıç aşamasında Bulanık DEMATEL uygulaması neticesinde elde edilen Toplam İlişki Matrisi'nden yararlanılmıştır. Söz konusu matristen hareketle Ağırlıklandırılmamış Süpermatris oluşturulmuştur. İkinci aşamada Ağırlıklandırılmış Süpermatris, son safhada ise Limit Süpermatris oluşturulmuş ve aşama aşama uygulama sonuçları Ek-2'de verilmiştir. Uygulama sonucunda her bir ölçütün ağırlıkları ise Tablo 8'de ortaya konmuştur. 
Tablo 8: Performans Ölçüt Ağırlıkları

\begin{tabular}{|c|c|}
\hline Performans Ölçütü & Ă̆ırlık \\
\hline Mükemmel Sipariş Karşılama Oranı (RL.1.1) & $11,04 \%$ \\
\hline Toplam Hizmet Maliyeti (CO 1.001) & $10,67 \%$ \\
\hline Sipariş Karşılama Çevrim Zamanı (RS.1.1) & $10,46 \%$ \\
\hline Nakitten Nakite Çevrim Zamanı (AM.1.1) & $10,26 \%$ \\
\hline Tedarik Zinciri Sabit Varlıkların Geri Dönüşü (AM.1.2) & $10,12 \%$ \\
\hline İşletme Sermayesinin Geri Dönüşü (AM.1.3) & $10,08 \%$ \\
\hline Üst Tedarik Zinciri Esnekliği (AG.1.1) & $9,39 \%$ \\
\hline Alt Tedarik Zinciri Adaptasyonu (AG.1.3) & $9,34 \%$ \\
\hline Üst Tedarik Zinciri Adaptasyonu (AG.1.2) & $9,33 \%$ \\
\hline Ortalama Riske Maruz Değer (AG. 1.4) & $9,31 \%$ \\
\hline
\end{tabular}

Çalışma kapsamındaki kullanılan performans ölçütlerinin AAS Yöntemi ile ağırlıklandırılması sonucunda en önemli ölçüt olarak ortaya çıkan Mükemmel Sipariş Karşılama Oranı, siparişlerin müşterinin isteğine göre doğru zamanda, doğru miktarda, tamamlanmış belgeleri ile hasarsız ulaşmasını ifade eder. Bu ölçütün önemi sadece kablo sektörü için değil tüm sektörler için geçerlidir. Müşterilerin zamanında ve tam olarak karşılanamayan istek ve ihtiyaçları zamanla müşterilerin tercihini başka işletmelerden yana kullanması sonucunu doğuracaktır. Ayrıca siparişi tam anlamda karşılanmayan müşteri şayet tercihini mevcut işletmeden yana kullandıysa bir sonraki siparişinde açığı kapatmak adına abartılı bir miktar sipariş geçebilir. Bu durum nihai müşteriden üreticilere doğru olan talep varyansının değişimi olarak bilinen kamçı etkisinin (bullwhip effect) oluşumunu hızlandırır. Kamçı etkisinde müşterinin talebindeki küçük dalgalanmalar zincir boyunca varyansını artırarak, üreticinin tedarikçilerine, nihai müşteri talebine göre daha fazla oranda sipariş geçmesi söz konusudur. Böylece aşırı stoklar oluşmakta ve işletmeler gereksiz yere depo maliyetine katlanmak zorunda kalmaktadır. Bu nedenle tedarik zinciri paydaşları arasındaki bilgi paylaşımının net olması olumsuz etkileri önlemek için çok önemlidir.

İkinci önemli ölçüt olan Toplam Hizmet Maliyeti müşteriye teslim edilen ve verilen hizmetin toplam tedarik zinciri maliyetidir. Bu kapsamda özellikle data kablosu ürün kaleminde ucuz uzak doğulu menşeili ürünlerin Türkiye pazarında karşılık bulması işletmelerin rekabet gücünü doğrudan etkilemektedir. Bu nedenle sektörde maliyetlerin çok iyi hesaplanması gerekmekte olup, rekabet üstünlüğü sağlamak için hedef müşteri kitlesine kalite/fiyat oranının önemi ve ürünlerin göreceli üstünlüğü vurgulanabilir.

Üçüncü önemli ölçüt olan Sipariş Karşılama Çevrim Zamanı, müşteri siparişlerinin yerine getirilme süresinin ortalama değerini ifade etmektedir. Kablo sektöründe en önemli hammadde olan metallerde (bakır/alüminyum vb.) yaşanabilecek global dar boğazlar Sipariş Karşılama Çevrim Zamanını doğrudan etkiyecektir. Bu noktada oluşabilecek tehditleri öngörerek zamanında tedarikçiler ile iş birliği yapabilen işletmelerin çevrim zamanı kısa olacaktır. Bu durum işletmeye sektörde rakipleri karşısında avantaj sağlayacak ve müşteri memnuniyetini sağlayacaktır.

Dördüncü, beşinci ve altıncı önemli ölçütler olan Nakitten Nakte Çevrim Zamanı, Tedarik Zinciri Sabit Varlıkların Geri Dönüşü ve İşletme Sermayesinin Geri Dönüşü ölçütlerinin tümü Varlık Yönetimi Etkinliği niteliği ile ilgilidir. Nakitten Nakte Çevrim Zamanı nakdin ürünlere ve servislere yatırıldığı zaman ile yatırımın nakit ürettiği zaman arasındaki sürekliliği ifade etmektedir. Çevrim zamanının uzun olması durumunda işletmenin işletme sermayesi ihtiyacı artacaktır. Buna göre işletmeler, çevrim zamanını etkileyen faktörleri iyi analiz ederek nakit yönetim politikalarını geliştirip daha etkin bir yönetim sergileyebilirler. Tahsilat sürelerinin kısaltılması, optimum stokla çalışılması ve borç ödeme takviminin iyileştirilmesi Nakitten Nakte Çevrim Zamanını kısaltmak için işletmelerce üzerinde aksiyon alınacak noktalardır. Tedarik Zinciri Sabit Varlıkların Geri Dönüş oranı sabit varlıkların işletmenin varlıkların gelir yaratma yönünde ne kadar etkin yönetildiğini ortaya koyar. Söz konusu oran atıl sabit varlıkların tespitine yönelik önemli bilgiler vermekte olup sektör için özellikle üretim hatlarının verimli kullanılması adına çok önemlidir. Üretim hatlarını etkin ve verimli kullanabilen işletmeler sektörde rekabet üstünlüğü sağlayabilmektedir. İşletme Sermayesinin Geri Dönüş oranı işletme sermayesinin işletme gelirine karşı büyüklüğünü göstermektedir. Kısa vadeli borçların ödenmesi ve işletmenin çalışma olanaklarının sağlanması için gerekli olan işletme sermayesi şirketlerin hayatta kalabilmeleri için çok önemlidir. Bu kapsamda dördüncü, beşinci ve altınc1 derecede önemli nitelikler kablo sektörü için varlık yönetimi etkinliğinin önemini ortaya koymaktadır. 
Diğer önemli ölçütlerden Üst Tedarik Zinciri Esnekliği işletmenin plansız ve sürdürülebilir olarak yüzde 20 fazla ürün teslim edebilme durumuna gelmek için gereken minimum zaman ile, Alt Tedarik Zinciri Adaptasyonu teslimattan 30 gün öncesinde siparişlerdeki sürdürülebilir azalma yüzdesi ile, Üst Tedarik Zinciri Adaptasyonu ise 30 günlük bir zaman dilimi içinde şirketin sürdürülebilir şekilde ulaşabileceği maksimum teslim ettiği miktardaki artış değeri ile ilgidir. Söz konusu üç ölçüt tamamen sektördeki esnekliğin önemini yansıtmaktadır. Teknoloji ve enerji sektöründeki yatırımlarının hızla artması sektörün ani sipariş değişikliklerine cevap verebilir olmasını gerektirmektedir. Bu kapsamda projelerin zamanında tamamlanması için müşteriler daha esnek işletmelerle çalışmayı tercih etmektedirler.

Son olarak Ortalama Riske Maruz Değer risk ile karşılaşma derecesini ifade eder. Kablo sektöründeki en önemli risk unsurları yoğunluklu olarak uluslararası metal borsası ve döviz kurudur. İthal hammaddelerin temininde yaşanabilecek problemler bütün ölçütleri doğrudan etkilemektedir. Genel olarak sektörde riski azaltmak için siparişe ilişkin detaylı planlamalar yapılmaya çalışılmaktadır. Müşterilerle yapılan görüşmeler ile uzun, orta ve kısa vadeli alım planları belirlenmeye ve risk azaltılmaya çalışılmaktadır.

\section{Sonuç ve değerlendirme}

Bu çalışmada kablo sektöründe SCOR Modeli bazlı bir performans seti baz alınarak performans niteliklerinin ve ölçütlerinin ilişki yapısı incelenmiş ve performans ölçütlerinin önem düzeyleri belirlenmiştir.

Yapılan uygulama neticesinde en yüksek D+R değeri olan Yanıt Verilebilirlik performans niteliğinin diğer nitelikler ile daha fazla ilişkiye sahip olduğu belirlenmiştir. Bu nedenle Hipotez-1 kabul edilmiştir. Başka unsurları etkileyen rol olan gönderici karakterde ortaya çıkan Yanıt Verilebilirlik, işletmenin siparişleri karşılayabilme yeteneği olarak ifade edilebilir. İşletmenin müşteri nezdinde kazanacağı güven, siparişlerin zamanında teslimi ile elde edilecek gelir ile nakit akışının düzenli ve öngörülebilir olması ve sermayenin hızlı dönüşü sayesinde ürünlerin maliyeti ve yeni yatırımlar noktasında işletmelere avantaj sağlanması, siparişlere yanıt verilebilme yeteneği ile doğrudan ilişkilidir. Ortiz-Barrios vd. (2017)'nin kablo sektörü için son derece önemli bir hammadde olan yüksek yoğunluklu polietilen tedarikçisi seçiminde ise Yenilik kriterinin en yüksek $D+R$ değere sahip olduğu görülmektedir. Bu durum kablonun imalatı noktasında yeniliğin önemini ortaya koymaktadır. Yenilikçi ürünlerin varlığı ve müşteri taleplerine yanıt verilebilirlik firmaların performansını artıran ve önceliklendirilmesi gereken unsurlar arasında gösterilebilir.

Kablo sektöründe performans ölçütlerinin önem ağırlıkları açısından en önemli ölçüt Mükemmel Sipariş Karşılama Oranı olarak belirlenmiştir. Bu nedenle Hipotez-2 reddedilmiştir. Bu durum kablo sektöründe siparişin eksiksiz bir şekilde tamamlanmasının maliyetten daha önemli olduğunu göstermektedir. İşletmelerin sipariş miktarında ve teslim zamanında belirlenen şartlara uymaması durumunda müşteri nezdinde güvenilirlik azalacak ve ödemeler konusunda yaşanacak olumsuzluklar neticesinde ise nakit akışında aksamalar yaşanacaktır. Bu nedenle işletmelerin faaliyetlerini sürdürebilmesi için siparişin tam olarak karşılanma durumuna dikkat edilmesi gerekmektedir. Mükemmel Sipariş Karşılama Oranı performans ölçütü SCOR modeline göre Güvenilirlik performans niteliği içerisinde değerlendirilse bile literatürdeki çalışmalar incelendiğinde teslimat başlığı altında da değerlendirilebileceği görülmektedir.

Literatür incelendiğinde tedarikçi seçiminde veya değerlendirilmesinde fiyat, kalite ve teslimat olmak üzere üç ana kriter öne çıkmaktadır (Öz ve Baykoç, 2004). Teslimat, tedarikçinin önceden belirlenen bir teslimat çizelgesine göre, satın alınan ürünlerin güvenilir bir şekilde teslim edilmesi sonucunda tedarik zinciri ilişkilerinin değerlendirilmesinde ve sürdürülmesinde her zaman için önemli bir kriterdir (Chan ve Kumar, 2006). Bu kapsamda SCOR modeli performans ölçütleri önem ağırlıkları açısından ilk üç sırada yer alan ölçütlerden ikisi teslimat başlıkları altında değerlendirilebilir (Mükemmel Sipariş Karşılama Oranı ve Sipariş Karşılama Çevrim Zamanı). Bu nedenle teslimat kriterinin hem performans değerlendirmelerinde hem de tedarikçi seçim süreçlerinde kritik bir öneme sahip olduğu söylenebilir.

Sektör için bütün ölçütler genel olarak değerlendirildiğinde bütün ölçütlerin birbirine yakın önem düzeylerine sahip olduğu görülmüştür. Bütün süreçlerin hiyerarşik ve birbirine sıkı sıkıya bağlı olması nedeniyle önem düzeyi en yüksek ölçütü sağlamak harcanan dikkat ve eforun önem düzeyi en az olan ölçüt için de yaklaşık olarak gösterilmesi gerekmektedir. Bu nedenle bu denli iç içe geçmiş süreçlerde yaşanabilecek en ufak bir problem zincirin tamamını etkilemektedir. Ülkemizde ve Dünyada özellikle teknoloji yatırımlarının giderek arttığı bu dönemde işletmelerin zamanında hammadde temin edememesi, işletme sermayesinin geri dönüşünün uzun olması nedeniyle üretim 
kapasitesinin düşmesi, maliyet optimizasyonunun yapılmaması, risk faktörlerinin dikkate alınmaması ve esnekliğe önem verilmemesi gibi durumlar doğrudan yatırım projelerini etkileyecek, dolayısıyla müşteri memnuniyetsizliği yaratacaktır. Birbirini doğrudan etkileyen çok sayıda süreç olduğundan dolayı kablo sektöründe performans ölçütlerinin önem düzeylerinin birbirine yakın olması doğal karşılanabilir.

Çalışma kablo sektöründe faaliyet gösteren on beş işletme temsilcisinden oluşan grup ile yapılmıştır. Aynı sektörde faaliyet gösteren diğer firmalar ile görüşme gerçekleştirilememiş olup, bu durum çalışmanın kıstını oluşturmaktadır. Bu nedenle Sanayi ve Ticaret Odasına kayıtlı bütün işletmeleri kapsayan bir çalışma, sektörü daha net olarak yansıtabilecektir.

Kablo sektörü özelinde literatürde SCOR modeli bazında bir çalışmaya rastlanılmamış olup, çalışmanın bu yönüyle literatürdeki önemli bir boşluğu doldurması beklenmektedir. Gelecekte yapılacak çalışmalarda farklı sektörlerdeki performans ölçütlerinin önem ağırlıkları belirlenebilir ve sektörler arası karşılaştırma yapılarak sektörel performans ölçütlerinde öncelik verilmesi gereken kavramlar belirlenebilir. Ayrıca farklı performans ölçüm yöntemleri ölçütlerinin kullanılabileceği bir çalışma yapılabilir ve elde edilecek bulgular neticesinde ülkemiz ve yurtdışı karşılaştırmalı çalışmalar yapılarak literatüre katkı sağlanabilir.

\section{Hakem Değerlendirmesi / Peer-review:}

Dış bağımsız

Externally peer-reviewed

\section{Çıkar Çatışması / Conflict of interests:}

Yazar(lar) çıkar çatışması bildirmemiştir.

The author(s) has (have) no conflict of interest to declare.

\section{Finansal Destek/ Grant Support:}

Yazar(lar) bu çalışma için finansal destek almadı̆̆ını beyan etmiştir.

The author(s) declared that this study has received no financial support.

\section{Kaynakça / Refernces}

Aksakal, E. ve Dağdeviren, M. (2010). ANP ve DEMATEL Yöntemleri ile Personel Seçimi Problemine Bütünleşik bir Yaklaşım. Gazi Üniversitesi Mühendislik ve Mimarlık Fakültesi Dergisi, 25(4), 905-910.

Albayrak, Ö. ve Erkayman, B. (2018). Bulanık Dematel ve Edas Yöntemleri Kullanılarak Sporcular İçin Akıllı Bileklik Seçimi. Ergonomi, 1(2), 92-102.

Alsoboa, S.S. (2017). The Influence of Economic Value Added and Returnon Assets on Created Shareholders Value: A Comparative Study in Jordanian Public Industrial Firms. International Journal of Economics and Finance, 9(4), 1-15.

Ar, İ. M. (2013). Trabzon İli İçin Kentsel Lojistik Stratejisi Seçimi: Birleştirilmiş SWOT Analizi-Analitik A ğ Süreci Yöntemi Uygulaması. II. Ulusal Lojistik ve Tedarik Zinciri Kongresi, 16-18 Mayıs, Aksaray Üniversitesi, Aksaray.

Ar, İ., Gökşen, H. ve Tuncer, M. (2015). Using Integrated DEMATEL-ANP-VIKOR Method for Supplier Selection in Cable Sector . Ege Academic Review, 15(2), 285-300.

Aramyan, L., Oude Lansink, A., Van Der Vorst, J.G.A.J. ve Van Kooten, O. (2007). Performance Measurement in Agri-Food Supply Chains: A Case Study. Supply Chain Management: An International Journal, 12(4), 304-315.

Askarany, D., Yazdıfar, H. ve Askary, S. (2010). Supply Chain Management, Activity-Based Costing and Organisational Factors. International Journal of Production Economics, 127(2), 238-248. 
Awan, A.G., Siddique, K. ve Sarwar, G. (2014). The effect of Economic Value Added on stock return: Evidence from selected companies of Karachi stock exchange. Research Journal of Finance and Accounting, 5(23), 140-153.

Bacher, A. (2004). Instrumente des Supply Chain Controlling. Gabler, Wiesbaden.

Başkol, M. (2013). Tedarik Zinciri Yönetimi, T.C. Anadolu Üniversitesi Yayını No: 2889 Açı̈öğretim Fakültesi Yayını No: 1846 Eskişehir.

Baykaşoğlu, A., Kaplanoğlu, V., Durmuşoğlu, Z. ve Şahin, C. (2013). Integrating Fuzzy DEMATEL and Fuzzy Hierarchical TOPSIS Methods for Truck Selection. Expert Systems With Applications, 40(3), 899-907.

Berrah, L. ve Cliville, V. (2007). Towards an Aggregation Performance Measurement System Model in A Supply Chain Context. Computers in Industry, 58(7), 709-719.

Bhagwat, R. ve Sharma, M. K. (2007a). Performance Measurement of Supply Chain Management: A Balanced Scorecard Approach. Computers and Industrial Engineering, 53(1), 43-62.

Bhagwat, R. ve Sharma, M. K. (2007b). Performance Measurement of Supply Chain Management Using the Analytical Hierachy Process. Production Planning and Control, 18(8), 666-680.

Bhagwat, R., Chan, F. ve Sharma, M. K. (2008). Performance Measurement Model for Supply Chain Management in Smes'. International Journal of Globalisation and Small Business, 2(4), 428- 445.

Bhagwat, R. ve Sharma, M. K. (2009). An Application of the Integrated Ahp-Pgp Model For Performance Measurement of Supply Chain Management. Production Planning E Control, 20(8), 678-690.

Bigliardi, B. ve Bottani, E. (2010). Performance Measurement in the Food Supply Chain: A Balanced Scorecard Approach. Facilities, 28(5/6), 249-260.

Boz Eravc1, D. (2020). Kurumların Dijital Dönüşümü: Büyük Veri. Çalışma İlişkileri Dergisi, 11(1) , 90112.

Cai, J., Liu, X., Xiao, Z. ve Liu, J. (2009). Improving Supply Chain Performance Management: A Systematic Approach to Analyzing Iterative Kpi Accomplishment. Decision Support System, 46(2), 512-521.

Chan, F.T. S. ve Chan H.K. (2004). Development of the Supplier Selection Model- A Case Study in the Advanced Technology Industry. Proceedings of the Institution of Mechanical Engineers, Part B: Journal of Engineering Manufacture, 218(12), 1807-1824.

Chan, F.T.S. ve Kumar, N. (2007). Global Supplier Development Considering Risk Factors Using Fuzzy Extended AHP-Based Approach. Omega The International Journal of Management Science, 35(4), 417-431.

Chan, F. T. S. ve Qi, H.J. (2003). An Innovative Performance Measurement Method for Supply Chain Management. Supply Chain Management: An International Journal, 8(3), 209-223.

Christopher, M. ve Lee, H. (2004). Mitigating Supply Chain Risk through Improved Confidece Building The Resilient Supply Chain. International Journal of Physical Distribution E Logistics Management, 34(5), 388-396.

Drzymalski, J., Odrey, N. ve Wilson, G. (2010). Aggregating Performance Measures of A MultiEchelon Supply Chain Using the Analytical Network and Analytical Hierarchy Process. International Journal of Services, Economics and Management, Economics and Management, 2(3/4), 286306.

Duran, O. ve Afonso, P. S. L. P. (2020). An Activity Based Costing Decision Model for Life Cycle Economic Assessment in Spare Parts Logistic Management. International Journal of Production Economics, 222, 107499.

Halim, Y.T., Eldeeb, M.S., Habib, E.E. ve Bassim, M.A. (2011). Supply Chain Performance Evaluation Through Eva in Hospitality Available at SSRN: https:/ /ssrn.com/abstract=1874931.

Fox, M. (1997). Supply Chain Management System, Department of Industrial Engineering, University of Toronto 
Frederico, G.F., Garza-Reyes, J.A., Kumar, A. ve Kumar, V. (2020). Performance Measurement for Supply Chains in the Industry 4.0 Era: A Balanced Scorecard Approach. International Journal of Productivity and Performance Management, 70(4), 789-807.

Gencer, C. ve Gürpinar, D. (2007). Analytic Network Process in Supplier Selection: A Case Study in an Electronic Firm. Applied Mathematical Modeling, 31(11), 2475-2486.

Gunasekaran, A., Patel, C., ve Tirtıroglu, E. (2001). Performance Measures and Metrics in a Supply Chain Environment. International Journal of Production and Operations Management, 21(1/2), 71-87.

Haghighi, P.S., Moradi, M. ve Salahi, M. (2014). Supplier Segmentation Using Fuzzy Linguistic Preference Relations and Fuzzy Clustering. International Journal of Intelligent Systems and Applications, 5, 76-82.

Hassanpour M. (2021). Classification of Five Iranian Chemical Industries Based on Economic ValueAdded. Central Asian Journal of Environmental Science and Technolgy Innovation, 2, 52-67.

Jharkharia, S. ve Shankar, R. (2007). Selection of Logistics Service Provider: An Analytic Network Process(ANP) Approach. Omega The International Journal of Management Science, 35(3), $274-289$.

Jing-Rung, C.-C.T. (2008). A Decision Framework for Supplier Rating and Purchase Allocation: A Case in the Semiconductor Industry. Computers $\mathcal{E}$ Industrial Engineering, 55(3), 634-646.

Kabloder, Kablo Sanayicileri Derneği (2020). Erişim Adresi: https://kabloder.org/wpcontent/uploads/2020/03/Kabloder-Brosur-Web-3.pdf, Erişim Tarihi : 20/07/2021.

Kannan, D., Khodaverdi, R., Olfat, L., Jafarian, A. ve Diabat, A. (2013). Integrated Fuzzy Multi Criteria Decision Making Method and Multi-Objective Programming Approach for Supplier Selection and Order Allocation in a Green Supply Chain. Journal of Cleaner Production, 47, 355-367.

Khaleie, S., Fasanghari, M. ve Tavassoli, E. (2012). Supplier Selection Using a Novel Intuitionist Fuzzy Clustering Approach. Applied Soft Computing, 12, 1741-1754.

Kuo, R. J., Wang, Y. C. ve Tien, F. C. (2010). Integration of Artificial Neural Network and MADA Methods for Green Supplier Selection. Journal of Cleaner Production, 18, 1161-1170.

Lai, K. H., Ngai, E.W.T. ve Cheng, T.C.E. (2002). Measures for Evaluating Supply Chain Performance in Transport Logistics. Transportation Research Part E, 38, 439-456.

Lee, H. L. ve Billington, C. (1992). Managing Supply Chain Inventory: Pitfalls and Opportunaties. Sloan Management Review, 33(3), 65-73.

Liberatore, M. J. ve Nydick, R. L. (1997). Group Decision Making in Higher Education Using the Analytic Hierarcy Process. Research in Higher Education, 38(5), 593-614.

Lima-Junior, F.R. ve Ribeiro, C.L.C. (2019). Predicting Supply Chain Performance Based on Scor ${ }^{\circledR}$ Metrics and Multilayer Perceptron Neural Networks. International Journal of Production Economics, 212, 19-38.

Lin, B., Collins, J. ve Su, R. K. (2001). Supply Chain Costing: An Activity-Based Perspective. International Journal of Physical Distribution Logistics Management, 31(10), 702-713.

Lin, C. T., Chen, C. B. ve Ting, Y. C. (2011). An ERP Model for Supplier Selection in Electronics Industry. Expert Systems with Applications, 38 (3), 1760-1765.

Lin, C.W., Chen, S.H. ve Tzeng, G.H. (2009). Constructing a Cognition Map of Alternative Fuel Vehicles Using the DEMATEL Method. Journal of Multi-Criteria Decision Analysis, 16, 5-19.

Lin, C.-J., ve Wu, W.-W. (2008). A Causal Analytical Method For Group Decision-Making Under Fuzzy Environment, Expert Systems with Applications, 34(1), 205-213.

Luthra, S., Govindan, K., Kannan, D., Mangla, S.K. ve Garg, C.P. (2017). An Integrated Framework for Sustainable Supplier Selection and Evaluation in Supply Chains. Journal of Cleaner Production, 140, 1686-1698.

Marwah, A., Thakar, G. ve Gupta, R. (2014). Determinants of Supply Chain Performance in the Indian Manufacturing Organizations. Proposed Conceptual Model, 5(1), 14-27.

Mentzer, J., Dewitt, W., Keebler, J., Min, S., Nix, N., Smith, C. ve Zacharia, Z. (2001). Defining Supply Chain Management. Journal of Business Logistics, 22 (2), 1-25. 
Monczka, R. M., Handfield, R. B. ve Trent, R. J. (2004). Purchasing and Supply Chain (with Infotrac) Hardcover, 3rd edition.

Mohamadi, A., Mowla, D., Abbasi, A. ve Askarifar, K. (2015). Using Thermodynamics Entropy to Modelling Economic Value Added Analysis of Manufacturing Firms (Iranian Chemical Industries Case Study). European Online Journal of Natural and Social Sciences: Proceedings, 4(1), 490-502.

Neely, A., Gregory, M. ve Platts, K. (1995). Performance Measurement System Design: A Literature Review and Research Agenda. International Journal of Operations \& Production Management, 15(4), 80116.

Nekooie, M.A., Sheikhalishahi, M. ve Hosnavi, R. (2015). Supplier Selection Considering Strategic and Operational Risks:A Combined Qualitative and Quantitative Approach. Production Engineering: Research and Development, 9, 665-673.

Ortiz-Barrios, M.A, Kucukaltan, B., Tinoco, D.C., Rodado, D.N. ve Jimenez, G. (2017). Strategic hybrid approach for selecting suppliers of high-density polyethylene. Journal of Multi-Criteria Decision Analysis, 24(5-6), 296-316.

Öz, E. ve Baykoç, Ö.F. (2004). Tedarikçi Seçimi Problemine Karar Teorisi Destekli Uzman Sistem Yaklaşımı. Gazi Üniversitesi Mühendislik Mimarlık Fakültesi Dergisi, 19(3), 275-286.

Paul, S.K. (2015). Supplier Selection for Managing Supply Risks in Supply Chain: A Fuzzy Approach. International Journal of Advanced Manufacturing Technology, 79, 657-664.

Palma-Mendoza, J.A. (2014). Analytical Hierarchy Process and Scor Model to Support Supply Chain Re-Design. International Journal of Information Management, 34(5), 634-638.

Reefke, H. ve Trocchi, M. (2013). Balanced Scorecard for Sustainable Supply Chains: Design and Development Guidelines. International Journal of Productivity and Performance Management, 62(8), 805-826.

Saad, S., Kunhu, N. ve Abdalah, M. (2016). A Fuzzy-AHP Multi-Criteria Decision-Making Model for Procurement Process. International Journal of Logistics Systems and Management, 23(1), 1-24.

Saaty, T.L. (1996). Decision Making with Dependence and Feedback: The Analytic Network Process, RWS Publications.

Saaty, T.L. ve Vargas, L.G. (2006). Decision Making with the Analytic Network Process: Economic, Political, Social and Technological Applications with Benefits, Opportunities, Costs and Risks, Springer Science, Business Media, LLC, New York, USA.

Saaty, T.L. (2009). Applications of Analytic Network Process in Entertainment. Iranian Journal of Operations Research, 1(2), 41-55.

Sarkar, A. ve Mohapatra, P.K.J. (2006). Evaluation of Supplier Capability and Performance: A Method for Supply Base Reduction. Journal of Purchasing and Supply Management, 12(3), 148-163.

Scc (2012). Supply Chain Council, Supply Chain Operations Reference Model Revision.

Soni, G. ve Kodali, R. (2010). Internal Benchmarking for Assessment of Supply Chain Performance. Benchmarking: An International Journal, 17(1), 44-76.

Tabriz, E. T. ve Alam, A. (2014). An Integrated Fuzzy DEMATEL-ANP-TOPSIS Methodology for Supplier Selection Proble. Global Journal of Management Studies and Researches, 1(2), 85-99.

Tanyaş, M. (2009). Tedarik Zinciri Yönetiminde Süreç Olgunluk Düzeyi Belirleme: SCOR-SOS Yaklaşımı, VII. Uluslararası Lojistik ve Tedarik Zinciri Kongresi, 06 Ekim, İstanbul.

Thanaraksakul, W. ve Phruksaphanrat B. (2009). Supplier Evaluation Framework Based on Balanced Scorecard With Integrated Corporate Social Responsibility Perspective. Proceedings of the International Multi Conference of Engineers and Computer Scientists, 2.

Theeranuphattana, A. ve John C.S.T. (2008). A Conceptual Model of Performance Measurement for Supply Chains Alternative Considerations, Journal of Manufacturing Technology Management, 19(1), $125-148$.

Tseng, Y-J. ve Lin, Y-H. (2005). A Model for Supplier Selection and Tasks Assignment. Journal of American Academy of Business, 6(2), 197-207. 
Tuzkaya, G., Önüt, S., Tuzkaya, U. ve Gülsün, B. (2008). An Analytic Network Process Approach for Locating Undesirable Facilities: An Example from İstanbul, Turkey. Journal of Environmental Management, 88, 970- 983.

Van Hoek, R. (1998). Measuring The Unmeasurable - Measuring and Improving Performance in the Supply Chain. Supply Chain Management, 3(4), 187-192.

Varma, S., Wadhwa, S. ve Deshmukh, S.G. (2008). Evaluating Petroleum Supply Chain Performance Application of Analytical Hierarchy Process to Balanced Scorecard. Asia Pacific Journal of Marketing and Logistics, 20(3), 343-356.

Verdecho, M., Rodriguez R. ve Alfaro-Saiz, J. (2013). Assessing Supplier Sustainability Using the Analytic Hierarchy Process. Collaborative Systems for Reindustrialization, 408, 577-585.

Wadhwa, V. ve Ravindran, AR. (2007). Vendor Selection in Outsourcing. Computers E Operations Research, 34(12), 3725-3737.

Wang, J.W., Cheng, C.H. ve Huang, K.C. (2008). Fuzzy Hierarchical TOPSIS for Supplier Selection. Applied Soft Computing, 9(1), 377-386.

Watt, D.J., Kayis, B. ve Willey K. (2010). The Relative Importance of Tender Evaluation and Contractor Selection Criteria. International Journal of Project Management, 28, 51-60.

Wondergem, J. (2004). Supply Chain Reference Model Includes All Elements of Demand Satisfaction, Supply Chain Management: Global Briefing. Global Purchasing and Supply Chain Strategies, 27-30.

Wong, W. P., Jaruphongsa, W., Lee, L. H. ve Wong, K. Y. (2007). A Preliminary Study On Using Data Envelopment Analysis (DEA) in Measuring Supply Chain Efficiency. International Journal of Applied Systemic Studies, 1(2), 188-207.

Wong, W.P. ve Wong, K.Y. (2007). Supply Chain Performance Measurement System Using DEA Modeling. Industrial Management E Data Systems, 107(3), 361-381.

Wong, W.P., Jaruphongsa, W. ve Lee, L.H. (2008). Supply Chain Performance Measurement System: A Monte Carlo DEA-Based Approach. International Journal of Industrial and Systems Engineering,3(2), 162-188.

Wong, W.P. (2009). Performance Evaluation of Supply Chain in Stochastic Environment: Using A Simulation Based DEA Framework'. International Journal of Business Performance and Supply Chain Modelling, 1(2/3), 203-228.

Wu, W.W. ve Lee Y.T. (2007). Developing Global Managers' Competencies Using the Fuzzy DEMATEL Method. Expert Systems With Applications, 32, 499-507.

Xia, W. ve Wu, Z. (2007). Supplier Selection with Multiple Criteria in Volume Discount Environments. Omega the International Journal of Management Science, 35(5), 494-504.

Yang, J. (2009). Integrative Performance Evaluation for Supply Chain System Based on Logarithm Triangular Fuzzy Number- AHP Method. Kybernetes, 38(10), 1760-1770.

Yörükoğlu, M. (2013). Tedarik Zinciri Yönetiminde Bilgi Sistemleri: Havacılık Yer Hizmetlerinde Uçuş Zamanlaması İçin Bilgi Paylaşım Modeli, Doktora Tezi, Hava Harp Okulu Havacılık ve Uzay Teknolojileri Enstitüsü.

Yurdakul, M. ve İç, Y. T. (2001). AHP ve Hedef Programlama Yöntemlerinin Sağlayıcı Seçimi Probleminde Kullanılması. XXII. Ulusal YA/EM Kongresi, Gazi Üniversitesi, Ankara.

Zanon, L. G., Munhoz A. R., Calache, L. D. D. R. ve Carpinetti L. C. R. (2020). A Decision Making Model Based on Fuzzy Inference to Predict the Impact of Scor® Indicators on Customer Perceived Value. International Journal of Production Economics, 223, 107520. 


\section{Ek-1}

\section{Bulanık Dematel Sonuçları}

Performans Niteliği - Direk İlişki Matrisi

\begin{tabular}{|c|c|c|c|c|c|c|c|c|c|c|c|c|c|c|c|}
\hline & \multicolumn{3}{|c|}{ Güvenirlilik } & \multicolumn{3}{|c|}{ Yanıt Verebilirlik } & \multicolumn{3}{|c|}{ Çeviklik } & \multicolumn{4}{|c|}{ Maliyet } & \multicolumn{2}{c|}{$\begin{array}{c}\text { Varlık Yönetimi } \\
\text { Etkinliği }\end{array}$} \\
\hline Güvenirlilik & 0,00 & 0,00 & 0,00 & 0,10 & 0,32 & 0,55 & 0,45 & 0,70 & 0,95 & 0,03 & 0,07 & 0,32 & 0,03 & 0,15 & 0,40 \\
\hline Yanıt Verebilirlik & 0,73 & 0,98 & 1,00 & 0,00 & 0,00 & 0,00 & 0,42 & 0,67 & 0,92 & 0,18 & 0,43 & 0,68 & 0,58 & 0,83 & 0,92 \\
\hline Çeviklik & 0,20 & 0,35 & 0,60 & 0,47 & 0,70 & 0,87 & 0,00 & 0,00 & 0,00 & 0,42 & 0,67 & 0,80 & 0,00 & 0,02 & 0,27 \\
\hline Maliyet & 0,00 & 0,08 & 0,33 & 0,08 & 0,25 & 0,50 & 0,25 & 0,42 & 0,67 & 0,00 & 0,00 & 0,00 & 0,08 & 0,32 & 0,55 \\
\hline Varlık Yönetimi Etkinliği & 0,65 & 0,88 & 0,93 & 0,65 & 0,90 & 1,00 & 0,70 & 0,95 & 1,00 & 0,67 & 0,92 & 0,98 & 0,00 & 0,00 & 0,00 \\
\hline
\end{tabular}

Performans Niteliği - Normalleştirilmiş Direk İlişki Matrisi

\begin{tabular}{|l|l|l|l|l|l|l|l|l|l|l|l|l|l|l|l|l|l|}
\hline & \multicolumn{3}{|c}{ Güvenirlilik } & \multicolumn{3}{|c|}{$\begin{array}{c}\text { Yanıt } \\
\text { Verebilirlik }\end{array}$} & \multicolumn{3}{c|}{ Çeviklik } & \multicolumn{3}{c|}{ Maliyet } & \multicolumn{2}{c|}{$\begin{array}{c}\text { Varlık Yönetimi } \\
\text { Etkinliği }\end{array}$} \\
\hline Güvenirlilik & 0,00 & 0,00 & 0,00 & 0,06 & 0,12 & 0,16 & 0,25 & 0,26 & 0,27 & 0,02 & 0,02 & 0,09 & 0,02 & 0,05 & 0,11 \\
\hline Yanit Verebilirlik & 0,40 & 0,36 & 0,28 & 0,00 & 0,00 & 0,00 & 0,23 & 0,24 & 0,26 & 0,10 & 0,16 & 0,19 & 0,32 & 0,30 & 0,26 \\
\hline Çeviklik & 0,11 & 0,13 & 0,17 & 0,26 & 0,26 & 0,25 & 0,00 & 0,00 & 0,00 & 0,23 & 0,24 & 0,23 & 0,00 & 0,01 & 0,08 \\
\hline Maliyet & 0,00 & 0,03 & 0,09 & 0,05 & 0,09 & 0,14 & 0,14 & 0,15 & 0,19 & 0,00 & 0,00 & 0,00 & 0,05 & 0,12 & 0,16 \\
\hline $\begin{array}{l}\text { Varlık Yönetimi } \\
\text { Etkinliği }\end{array}$ & 0,36 & 0,32 & 0,26 & 0,36 & 0,33 & 0,28 & 0,39 & 0,35 & 0,28 & 0,37 & 0,34 & 0,28 & 0,00 & 0,00 & 0,00 \\
\hline
\end{tabular}

Performans Niteliği - Toplam Bulanık İlişki Matrisi

\begin{tabular}{|l|l|l|l|l|l|l|l|l|l|l|l|l|l|l|l|l|}
\hline & \multicolumn{3}{|c}{ Güvenirlilik } & \multicolumn{3}{|c|}{$\begin{array}{c}\text { Yanıt } \\
\text { Verebilirlik }\end{array}$} & \multicolumn{3}{c|}{ Çeviklik } & \multicolumn{4}{c|}{ Maliyet } & \multicolumn{3}{c|}{$\begin{array}{c}\text { Varlık Yönetimi } \\
\text { Etkinliği }\end{array}$} \\
\hline Güvenirlilik & 0,16 & 0,30 & 0,52 & 0,21 & 0,40 & 0,67 & 0,40 & 0,56 & 0,83 & 0,17 & 0,31 & 0,59 & 0,10 & 0,23 & 0,50 \\
\hline Yanıt Verebilirlik & 0,87 & 0,94 & 1,00 & 0,47 & 0,64 & 0,79 & 0,82 & 0,98 & 1,14 & 0,54 & 0,74 & 0,92 & 0,51 & 0,64 & 0,81 \\
\hline Çeviklik & 0,38 & 0,49 & 0,71 & 0,44 & 0,57 & 0,78 & 0,32 & 0,44 & 0,68 & 0,41 & 0,54 & 0,74 & 0,17 & 0,27 & 0,52 \\
\hline Maliyet & 0,13 & 0,32 & 0,58 & 0,17 & 0,36 & 0,63 & 0,27 & 0,46 & 0,75 & 0,12 & 0,27 & 0,49 & 0,11 & 0,28 & 0,52 \\
\hline $\begin{array}{l}\text { Varlık Yönetimi } \\
\text { Etkinliği }\end{array}$ & 0,92 & 1,01 & 1,05 & 0,83 & 0,99 & 1,08 & 1,04 & 1,16 & 1,23 & 0,82 & 0,96 & 1,04 & 0,32 & 0,47 & 0,65 \\
\hline
\end{tabular}

Performans Niteliği - Durulaştırılmış Toplam Bulanık İlişki Matrisi

\begin{tabular}{|l|c|c|c|c|c|}
\hline & Güvenirlilik & $\begin{array}{c}\text { Yanıt } \\
\text { Verebilirlik }\end{array}$ & Çeviklik & Maliyet & $\begin{array}{c}\text { Varlık } \\
\text { Yönetimi } \\
\text { Etkinliği }\end{array}$ \\
\hline Güvenirlilik & 0,32 & 0,42 & 0,59 & 0,34 & 0,26 \\
\hline Yanıt Verebilirlik & 0,94 & 0,63 & 0,98 & 0,73 & 0,65 \\
\hline Çeviklik & 0,52 & 0,59 & 0,47 & 0,56 & 0,31 \\
\hline Maliyet & 0,34 & 0,38 & 0,48 & 0,29 & 0,30 \\
\hline Varlık Yönetimi Etkinliği & 1,00 & 0,97 & 1,15 & 0,94 & 0,48 \\
\hline
\end{tabular}


Performans Ölçütü - Direk İlişki Matrisi

\begin{tabular}{|c|c|c|c|c|c|c|c|c|c|c|c|c|c|c|c|c|c|c|c|c|c|c|c|c|c|c|c|c|c|c|}
\hline & \multicolumn{3}{|c|}{ (RL 1.1) } & \multicolumn{3}{|c|}{ (RS 1.1) } & \multicolumn{3}{|c|}{ (AG.1.1) } & \multicolumn{3}{|c|}{ (AG.1.2) } & \multicolumn{3}{|c|}{ (AG.1.3) } & \multicolumn{3}{|c|}{ (AG. 1.4) } & \multicolumn{3}{|c|}{ (CO 1.001) } & \multicolumn{3}{|c|}{ (AM.1.1) } & \multicolumn{3}{|c|}{ (AM.1.2) } & \multicolumn{3}{|c|}{ (AM.1.3) } \\
\hline (RL 1.1) & 0,00 & 0,00 & 0,00 & 0,10 & 0,35 & 0,60 & 0,67 & 0,92 & 1,00 & 0,63 & 0,88 & 1,00 & 0,48 & 0,73 & 0,98 & 0,37 & 0,62 & 0,87 & 0,35 & 0,60 & 0,80 & 0,35 & 0,60 & 0,85 & 0,37 & 0,62 & 0,87 & 0,40 & 0,65 & 0,90 \\
\hline (RS 1.1) & 0,38 & 0,63 & 0,88 & 0,00 & 0,00 & 0,00 & 0,27 & 0,52 & 0,77 & 0,25 & 0,50 & 0,75 & 0,47 & 0,72 & 0,97 & 0,28 & 0,53 & 0,78 & 0,03 & 0,15 & 0,40 & 0,68 & 0,93 & 0,97 & 0,47 & 0,72 & 0,97 & 0,62 & 0,87 & 0,93 \\
\hline (AG.1.1) & 0,47 & 0,72 & 0,97 & 0,68 & 0,93 & 0,97 & 0,00 & 0,00 & 0,00 & 0,45 & 0,70 & 0,95 & 0,28 & 0,53 & 0,78 & 0,30 & 0,55 & 0,78 & 0,10 & 0,30 & 0,55 & 0,00 & 0,12 & 0,37 & 0,03 & 0,22 & 0,47 & 0,02 & 0,08 & 0,33 \\
\hline (AG.1.2) & 0,45 & 0,70 & 0,95 & 0,12 & 0,37 & 0,62 & 0,13 & 0,38 & 0,60 & 0,00 & 0,00 & 0,00 & 0,03 & 0,28 & 0,53 & 0,22 & 0,47 & 0,72 & 0,22 & 0,47 & 0,72 & 0,05 & 0,15 & 0,40 & 0,12 & 0,35 & 0,60 & 0,00 & 0,12 & 0,37 \\
\hline (AG.1.3) & 0,45 & 0,70 & 0,95 & 0,00 & 0,25 & 0,50 & 0,50 & 0,75 & 1,00 & 0,32 & 0,57 & 0,78 & 0,00 & 0,00 & 0,00 & 0,03 & 0,28 & 0,53 & 0,25 & 0,50 & 0,75 & 0,00 & 0,15 & 0,40 & 0,00 & 0,17 & 0,42 & 0,02 & 0,15 & 0,40 \\
\hline (AG. 1.4) & 0,53 & 0,78 & 1,00 & 0,68 & 0,93 & 0,97 & 0,53 & 0,78 & 1,00 & 0,60 & 0,85 & 1,00 & 0,57 & 0,82 & 1,00 & 0,00 & 0,00 & 0,00 & 0,60 & 0,85 & 1,00 & 0,35 & 0,47 & 0,60 & 0,25 & 0,37 & 0,60 & 0,37 & 0,57 & 0,78 \\
\hline (CO 1.001) & 0,05 & 0,28 & 0,52 & 0,02 & 0,03 & 0,28 & 0,10 & 0,20 & 0,45 & 0,45 & 0,70 & 0,83 & 0,28 & 0,53 & 0,72 & 0,38 & 0,63 & 0,82 & 0,00 & 0,00 & 0,00 & 0,45 & 0,70 & 0,95 & 0,45 & 0,70 & 0,95 & 0,65 & 0,90 & 0,95 \\
\hline (AM.1.1) & 0,68 & 0,93 & 0,98 & 0,57 & 0,82 & 1,00 & 0,53 & 0,78 & 1,00 & 0,72 & 0,97 & 1,00 & 0,37 & 0,62 & 0,87 & 0,47 & 0,72 & 0,97 & 0,72 & 0,97 & 1,00 & 0,00 & 0,00 & 0,00 & 0,07 & 0,20 & 0,45 & 0,12 & 0,20 & 0,43 \\
\hline (AM.1.2) & 0,70 & 0,95 & 1,00 & 0,07 & 0,22 & 0,47 & 0,75 & 1,00 & 1,00 & 0,53 & 0,78 & 1,00 & 0,47 & 0,72 & 0,97 & 0,50 & 0,75 & 0,98 & 0,23 & 0,35 & 0,60 & 0,72 & 0,97 & 1,00 & 0,00 & 0,00 & 0,00 & 0,25 & 0,48 & 0,68 \\
\hline (AM.1.3) & 0,72 & 0,97 & 0,98 & 0,40 & 0,65 & 0,87 & 0,50 & 0,75 & 0,98 & 0,70 & 0,95 & 1,00 & 0,62 & 0,87 & 1,00 & 0,48 & 0,73 & 0,98 & 0,72 & 0,97 & 1,00 & 0,55 & 0,80 & 1,00 & 0,68 & 0,93 & 0,98 & 0,00 & 0,00 & 0,00 \\
\hline
\end{tabular}

Performans Ölçütü - Normalleştirilmiş Direk İlişki Matrisi

\begin{tabular}{|c|c|c|c|c|c|c|c|c|c|c|c|c|c|c|c|c|c|c|c|c|c|c|c|c|c|c|c|c|c|c|}
\hline & \multicolumn{3}{|c|}{ (RL 1.1) } & \multicolumn{3}{|c|}{ (RS 1.1) } & \multicolumn{3}{|c|}{ (AG.1.1) } & \multicolumn{3}{|c|}{ (AG.1.2) } & \multicolumn{3}{|c|}{ (AG.1.3) } & \multicolumn{3}{|c|}{ (AG.1.4) } & \multicolumn{3}{|c|}{ (CO 1.001) } & \multicolumn{3}{|c|}{ (AM.1.1) } & \multicolumn{3}{|c|}{ (AM.1.2) } & \multicolumn{3}{|c|}{ (AM.1.3) } \\
\hline (RL 1.1) & 0,00 & 0,00 & 0,00 & 0,02 & 0,05 & 0,07 & 0,14 & 0,13 & 0,12 & 0,14 & 0,13 & 0,12 & 0,10 & 0,11 & 0,12 & 0,08 & 0,09 & 0,10 & 0,08 & 0,09 & 0,10 & 0,08 & 0,09 & 0,10 & 0,08 & 0,09 & 0,10 & 0,09 & 0,09 & 0,11 \\
\hline (RS 1.1) & 0,08 & 0,09 & 0,11 & 0,00 & 0,00 & 0,00 & 0,06 & 0,07 & 0,09 & 0,05 & 0,07 & 0,09 & 0,10 & 0,10 & 0,12 & 0,06 & 0,08 & 0,09 & 0,01 & 0,02 & 0,05 & 0,15 & 0,14 & 0,12 & 0,10 & 0,10 & 0,12 & 0,13 & 0,13 & 0,11 \\
\hline (AG.1.1) & 0,10 & 0,10 & 0,12 & 0,15 & 0,14 & 0,12 & 0,00 & 0,00 & 0,00 & 0,10 & 0,10 & 0,11 & 0,06 & 0,08 & 0,09 & 0,06 & 0,08 & 0,09 & 0,02 & 0,04 & 0,07 & 0,00 & 0,02 & 0,04 & 0,01 & 0,03 & 0,06 & 0,00 & 0,01 & 0,04 \\
\hline (AG.1.2) & 0,10 & 0,10 & 0,11 & 0,03 & 0,05 & 0,07 & 0,03 & 0,06 & 0,07 & 0,00 & 0,00 & 0,00 & 0,01 & 0,04 & 0,06 & 0,05 & 0,07 & 0,09 & 0,05 & 0,07 & 0,09 & 0,01 & 0,02 & 0,05 & 0,03 & 0,05 & 0,07 & 0,00 & 0,02 & 0,04 \\
\hline (AG.1.3) & 0,10 & 0,10 & 0,11 & 0,00 & 0,04 & 0,06 & 0,11 & 0,11 & 0,12 & 0,07 & 0,08 & 0,09 & 0,00 & 0,00 & 0,00 & 0,01 & 0,04 & 0,06 & 0,05 & 0,07 & 0,09 & 0,00 & 0,02 & 0,05 & 0,00 & 0,02 & 0,05 & 0,00 & 0,02 & 0,05 \\
\hline (AG.1.4) & 0,11 & 0,11 & 0,12 & 0,15 & 0,14 & 0,12 & 0,11 & 0,11 & 0,12 & 0,13 & 0,12 & 0,12 & 0,12 & 0,12 & 0,12 & 0,00 & 0,00 & 0,00 & 0,13 & 0,12 & 0,12 & 0,08 & 0,07 & 0,07 & 0,05 & 0,05 & 0,07 & 0,08 & 0,08 & 0,09 \\
\hline (CO 1.001) & 0,01 & 0,04 & 0,06 & 0,00 & 0,00 & 0,03 & 0,02 & 0,03 & 0,05 & 0,10 & 0,10 & 0,10 & 0,06 & 0,08 & 0,09 & 0,08 & 0,09 & 0,10 & 0,00 & 0,00 & 0,00 & 0,10 & 0,10 & 0,11 & 0,10 & 0,10 & 0,11 & 0,14 & 0,13 & 0,11 \\
\hline (AM.1.1) & 0,15 & 0,14 & 0,12 & 0,12 & 0,12 & 0,12 & 0,11 & 0,11 & 0,12 & 0,15 & 0,14 & 0,12 & 0,08 & 0,09 & 0,10 & 0,10 & 0,10 & 0,12 & 0,15 & 0,14 & 0,12 & 0,00 & 0,00 & 0,00 & 0,01 & 0,03 & 0,05 & 0,03 & 0,03 & 0,05 \\
\hline (AM.1.2) & 0,15 & 0,14 & 0,12 & 0,01 & 0,03 & 0,06 & 0,16 & 0,14 & 0,12 & 0,11 & 0,11 & 0,12 & 0,10 & 0,10 & 0,12 & 0,11 & 0,11 & 0,12 & 0,05 & 0,05 & 0,07 & 0,15 & 0,14 & 0,12 & 0,00 & 0,00 & 0,00 & 0,05 & 0,07 & 0,08 \\
\hline (AM.1.3) & 0,15 & 0,14 & 0,12 & 0,09 & 0,09 & 0,10 & 0,11 & 0,11 & 0,12 & 0,15 & 0,14 & 0,12 & 0,13 & 0,13 & 0,12 & 0,10 & 0,11 & 0,12 & 0,15 & 0,14 & 0,12 & 0,12 & 0,12 & 0,12 & 0,15 & 0,14 & 0,12 & 0,00 & 0,00 & 0,00 \\
\hline
\end{tabular}


Performans Ölçütü - Toplam Bulanık İlişki Matrisi

\begin{tabular}{|c|c|c|c|c|c|c|c|c|c|c|c|c|c|c|c|c|c|c|c|c|c|c|c|c|c|c|c|c|c|c|}
\hline & \multicolumn{3}{|c|}{ (RL 1.1) } & \multicolumn{3}{|c|}{ (RS 1.1) } & \multicolumn{3}{|c|}{ (AG.1.1) } & \multicolumn{3}{|c|}{ (AG.1.2) } & \multicolumn{3}{|c|}{ (AG.1.3) } & \multicolumn{3}{|c|}{ (AG.1.4) } & \multicolumn{3}{|c|}{ (CO 1.001) } & \multicolumn{3}{|c|}{ (AM.1.1) } & \multicolumn{3}{|c|}{ (AM.1.2) } & \multicolumn{3}{|c|}{ (AM.1.3) } \\
\hline (RL 1.1) & 0,23 & 0,33 & 0,61 & 0,16 & 0,29 & 0,54 & 0,33 & 0,42 & 0,69 & 0,36 & 0,46 & 0,73 & 0,27 & 0,39 & 0,69 & 0,23 & 0,35 & 0,65 & 0,23 & 0,34 & 0,60 & 0,21 & 0,31 & 0,57 & 0,19 & 0,30 & 0,57 & 0,20 & 0,29 & 0,53 \\
\hline (RS 1.1) & 0,32 & 0,42 & 0,69 & 0,15 & 0,24 & 0,46 & 0,28 & 0,38 & 0,65 & 0,31 & 0,41 & 0,68 & 0,29 & 0,38 & 0,66 & 0,22 & 0,34 & 0,62 & 0,19 & 0,29 & 0,54 & 0,30 & 0,36 & 0,57 & 0,22 & 0,31 & 0,56 & 0,25 & 0,31 & 0,52 \\
\hline (AG.1.1) & 0,23 & 0,32 & 0,59 & 0,22 & 0,29 & 0,48 & 0,13 & 0,21 & 0,46 & 0,23 & 0,33 & 0,59 & 0,17 & 0,27 & 0,55 & 0,16 & 0,26 & 0,52 & 0,12 & 0,22 & 0,47 & 0,10 & 0,18 & 0,43 & 0,09 & 0,18 & 0,43 & 0,09 & 0,16 & 0,39 \\
\hline (AG.1.2) & 0,18 & 0,28 & 0,55 & 0,08 & 0,19 & 0,41 & 0,11 & 0,23 & 0,49 & 0,10 & 0,20 & 0,45 & 0,08 & 0,21 & 0,48 & 0,11 & 0,22 & 0,48 & 0,11 & 0,21 & 0,45 & 0,07 & 0,16 & 0,40 & 0,08 & 0,17 & 0,41 & 0,06 & 0,14 & 0,36 \\
\hline (AG.1.3) & 0,17 & 0,28 & 0,55 & 0,06 & 0,17 & 0,41 & 0,18 & 0,28 & 0,54 & 0,16 & 0,28 & 0,54 & 0,07 & 0,17 & 0,43 & 0,07 & 0,20 & 0,47 & 0,11 & 0,22 & 0,46 & 0,05 & 0,16 & 0,40 & 0,05 & 0,15 & 0,40 & 0,05 & 0,14 & 0,37 \\
\hline (AG.1.4) & 0,37 & 0,45 & 0,72 & 0,30 & 0,37 & 0,58 & 0,35 & 0,43 & 0,69 & 0,40 & 0,48 & 0,73 & 0,33 & 0,42 & 0,69 & 0,19 & 0,28 & 0,55 & 0,31 & 0,39 & 0,62 & 0,25 & 0,32 & 0,55 & 0,20 & 0,28 & 0,54 & 0,23 & 0,30 & 0,53 \\
\hline (CO 1.001) & 0,22 & 0,32 & 0,58 & 0,13 & 0,21 & 0,44 & 0,20 & 0,29 & 0,55 & 0,30 & 0,39 & 0,62 & 0,22 & 0,32 & 0,57 & 0,22 & 0,31 & 0,56 & 0,16 & 0,23 & 0,44 & 0,23 & 0,29 & 0,51 & 0,20 & 0,27 & 0,50 & 0,23 & 0,29 & 0,47 \\
\hline (AM.1.1) & 0,38 & 0,45 & 0,70 & 0,27 & 0,35 & 0,57 & 0,32 & 0,41 & 0,67 & 0,40 & 0,47 & 0,71 & 0,27 & 0,38 & 0,66 & 0,27 & 0,36 & 0,64 & 0,32 & 0,39 & 0,61 & 0,17 & 0,24 & 0,47 & 0,16 & 0,25 & 0,51 & 0,17 & 0,24 & 0,48 \\
\hline (AM.1.2) & 0,40 & 0,47 & 0,71 & 0,19 & 0,28 & 0,52 & 0,39 & 0,45 & 0,68 & 0,39 & 0,47 & 0,71 & 0,30 & 0,40 & 0,67 & 0,28 & 0,38 & 0,65 & 0,24 & 0,33 & 0,57 & 0,30 & 0,37 & 0,58 & 0,13 & 0,22 & 0,46 & 0,19 & 0,27 & 0,50 \\
\hline (AM.1.3) & 0,47 & 0,55 & 0,79 & 0,28 & 0,38 & 0,62 & 0,40 & 0,49 & 0,75 & 0,49 & 0,56 & 0,80 & 0,38 & 0,48 & 0,75 & 0,33 & 0,44 & 0,72 & 0,38 & 0,46 & 0,68 & 0,33 & 0,41 & 0,65 & 0,31 & 0,40 & 0,63 & 0,18 & 0,26 & 0,49 \\
\hline
\end{tabular}

Performans Ölçütü - Durulaştırılmış Toplam İlişki Matrisi

\begin{tabular}{|c|c|c|c|c|c|c|c|c|c|c|}
\hline & (RL 1.1) & (RS 1.1) & (AG.1.1) & (AG.1.2) & (AG.1.3) & (AG.1.4) & (CO 1.001) & (AM.1.1) & (AM.1.2) & (AM.1.3) \\
\hline (RL 1.1) & 0,38 & 0,32 & 0,47 & 0,50 & 0,43 & 0,39 & 0,38 & 0,35 & 0,34 & 0,33 \\
\hline (RS 1.1) & 0,46 & 0,27 & 0,42 & 0,45 & 0,43 & 0,38 & 0,33 & 0,40 & 0,35 & 0,35 \\
\hline (AG.1.1) & 0,37 & 0,32 & 0,25 & 0,37 & 0,32 & 0,30 & 0,26 & 0,22 & 0,22 & 0,20 \\
\hline (AG.1.2) & 0,32 & 0,22 & 0,27 & 0,24 & 0,24 & 0,26 & 0,25 & 0,20 & 0,21 & 0,17 \\
\hline (AG.1.3) & 0,32 & 0,20 & 0,32 & 0,31 & 0,21 & 0,23 & 0,25 & 0,19 & 0,19 & 0,18 \\
\hline (AG.1.4) & 0,50 & 0,41 & 0,47 & 0,52 & 0,46 & 0,33 & 0,43 & 0,36 & 0,33 & 0,34 \\
\hline (CO 1.001) & 0,36 & 0,24 & 0,33 & 0,42 & 0,36 & 0,35 & 0,26 & 0,33 & 0,31 & 0,32 \\
\hline (AM.1.1) & 0,50 & 0,38 & 0,45 & 0,52 & 0,42 & 0,41 & 0,43 & 0,28 & 0,29 & 0,28 \\
\hline (AM.1.2) & 0,51 & 0,32 & 0,49 & 0,51 & 0,44 & 0,42 & 0,37 & 0,40 & 0,26 & 0,31 \\
\hline (AM.1.3) & 0,59 & 0,42 & 0,53 & 0,60 & 0,52 & 0,48 & 0,49 & 0,45 & 0,43 & 0,30 \\
\hline
\end{tabular}




\section{Ek-2}

\section{Aas Sonuçları}

Ağırlıklandırılmamış Süper Matris

\begin{tabular}{|c|c|c|c|c|c|c|c|c|c|c|}
\hline & (RL 1.1) & (RS 1.1) & (AG.1.1) & (AG.1.2) & (AG.1.3) & (AG.1.4) & (CO 1.001) & (AM.1.1) & (AM.1.2) & (AM.1.3) \\
\hline (RL 1.1) & 0,097 & 0,082 & 0,120 & 0,129 & 0,111 & 0,101 & 0,098 & 0,091 & 0,087 & 0,084 \\
\hline (RS 1.1) & 0,120 & 0,071 & 0,110 & 0,118 & 0,112 & 0,099 & 0,085 & 0,103 & 0,091 & 0,091 \\
\hline (AG.1.1) & 0,130 & 0,113 & 0,090 & 0,132 & 0,112 & 0,105 & 0,090 & 0,079 & 0,078 & 0,071 \\
\hline (AG.1.2) & 0,136 & 0,091 & 0,112 & 0,100 & 0,103 & 0,108 & 0,104 & 0,084 & 0,088 & 0,074 \\
\hline (AG.1.3) & 0,135 & 0,084 & 0,132 & 0,131 & 0,086 & 0,096 & 0,105 & 0,080 & 0,078 & 0,073 \\
\hline (AG.1.4) & 0,121 & 0,098 & 0,114 & 0,126 & 0,112 & 0,079 & 0,103 & 0,087 & 0,079 & 0,081 \\
\hline (CO 1.001) & 0,110 & 0,074 & 0,101 & 0,128 & 0,108 & 0,106 & 0,080 & 0,101 & 0,095 & 0,097 \\
\hline (AM.1.1) & 0,125 & 0,097 & 0,115 & 0,130 & 0,106 & 0,103 & 0,108 & 0,070 & 0,074 & 0,072 \\
\hline (AM.1.2) & 0,127 & 0,079 & 0,122 & 0,126 & 0,109 & 0,104 & 0,091 & 0,100 & 0,064 & 0,076 \\
\hline (AM.1.3) & 0,122 & 0,086 & 0,111 & 0,125 & 0,109 & 0,100 & 0,103 & 0,093 & 0,090 & 0,062 \\
\hline
\end{tabular}

Ağırlıklandırılmış Süper Matris

\begin{tabular}{|c|c|c|c|c|c|c|c|c|c|c|}
\hline & (RL 1.1) & (RS 1.1) & (AG.1.1) & (AG.1.2) & (AG.1.3) & (AG.1.4) & (CO 1.001) & (AM.1.1) & (AM.1.2) & (AM.1.3) \\
\hline (RL 1.1) & 0,016 & 0,018 & 0,037 & 0,039 & 0,034 & 0,031 & 0,017 & 0,012 & 0,012 & 0,011 \\
\hline (RS 1.1) & 0,029 & 0,011 & 0,027 & 0,029 & 0,028 & 0,025 & 0,016 & 0,017 & 0,015 & 0,015 \\
\hline AG.1.1) & 0,028 & 0,027 & 0,017 & 0,025 & 0,022 & 0,020 & 0,021 & 0,010 & 0,010 & 0,009 \\
\hline (AG.1.2) & 0,029 & 0,022 & 0,022 & 0,019 & 0,020 & 0,021 & 0,024 & 0,011 & 0,011 & 0,009 \\
\hline (AG.1.3) & 0,029 & 0,020 & 0,025 & 0,025 & 0,017 & 0,019 & 0,024 & 0,010 & 0,010 & 0,009 \\
\hline (AG.1.4) & 0,026 & 0,023 & 0,022 & 0,024 & 0,021 & 0,015 & 0,024 & 0,011 & 0,010 & 0,010 \\
\hline (CO 1.001) & 0,021 & 0,016 & 0,027 & 0,035 & 0,029 & 0,029 & 0,013 & 0,017 & 0,016 & 0,016 \\
\hline (AM.1.1) & 0,028 & 0,021 & 0,029 & 0,033 & 0,027 & 0,026 & 0,022 & 0,007 & 0,008 & 0,008 \\
\hline (AM.1.2) & 0,028 & 0,017 & 0,031 & 0,032 & 0,028 & 0,026 & 0,019 & 0,011 & 0,007 & 0,008 \\
\hline (AM.1.3) & 0,027 & 0,018 & 0,028 & 0,032 & 0,027 & 0,025 & 0,021 & 0,010 & 0,010 & 0,007 \\
\hline
\end{tabular}

Limit Süper Matris

\begin{tabular}{|c|c|c|c|c|c|c|c|c|c|c|}
\hline & (RL 1.1) & (RS 1.1) & (AG.1.1) & (AG.1.2) & (AG.1.3) & (AG.1.4) & (CO 1.001) & (AM.1.1) & (AM.1.2) & (AM.1.3) \\
\hline (RL 1.1) & 0,000182 & 0,000182 & 0,000182 & 0,000182 & 0,000182 & 0,000182 & 0,000182 & 0,000182 & 0,000182 & 0,000182 \\
\hline (RS 1.1) & 0,000172 & 0,000172 & 0,000172 & 0,000172 & 0,000172 & 0,000172 & 0,000172 & 0,000172 & 0,000172 & 0,000172 \\
\hline (AG.1.1) & 0,000155 & 0,000155 & 0,000155 & 0,000155 & 0,000155 & 0,000155 & 0,000155 & 0,000155 & 0,000155 & 0,000155 \\
\hline (AG.1.2) & 0,000154 & 0,000154 & 0,000154 & 0,000154 & 0,000154 & 0,000154 & 0,000154 & 0,000154 & 0,000154 & 0,000154 \\
\hline (AG.1.3) & 0,000154 & 0,000154 & 0,000154 & 0,000154 & 0,000154 & 0,000154 & 0,000154 & 0,000154 & 0,000154 & 0,000154 \\
\hline (AG.1.4) & 0,000153 & 0,000153 & 0,000153 & 0,000153 & 0,000153 & 0,000153 & 0,000153 & 0,000153 & 0,000153 & 0,000153 \\
\hline (CO 1.001) & 0,000176 & 0,000176 & 0,000176 & 0,000176 & 0,000176 & 0,000176 & 0,000176 & 0,000176 & 0,000176 & 0,000176 \\
\hline (AM.1.1) & 0,000169 & 0,000169 & 0,000169 & 0,000169 & 0,000169 & 0,000169 & 0,000169 & 0,000169 & 0,000169 & 0,000169 \\
\hline (AM.1.2) & 0,000167 & 0,000167 & 0,000167 & 0,000167 & 0,000167 & 0,000167 & 0,000167 & 0,000167 & 0,000167 & 0,000167 \\
\hline (AM.1.3) & 0,000166 & 0,000166 & 0,000166 & 0,000166 & 0,000166 & 0,000166 & 0,000166 & 0,000166 & 0,000166 & 0,000166 \\
\hline
\end{tabular}

